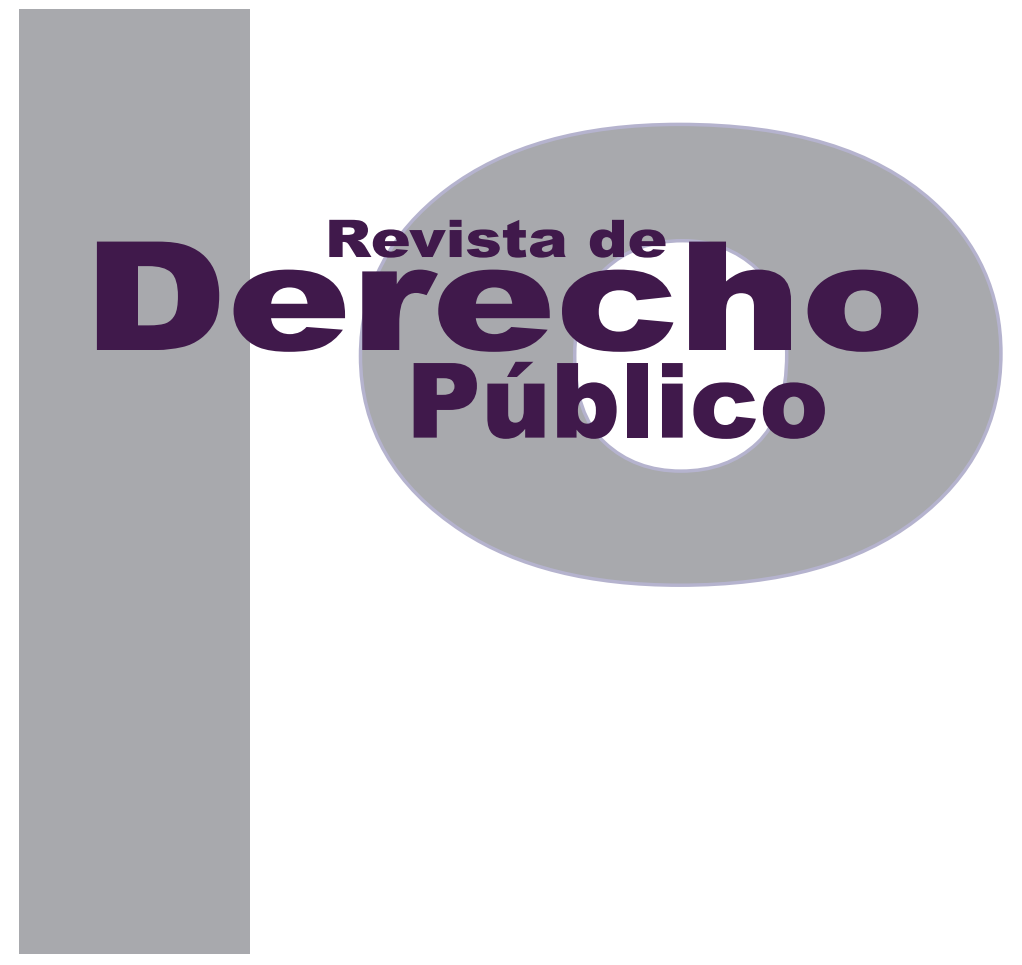

\title{
REPARACIÓN ADMINISTRATIVA, EFICACIA DE LA ACCIÓN DE TUTELA Y VÍCTIMAS DEL CONFLICTO ARMADO
}

\author{
Pablo Ernesto Medrano Moreno
}

DOI: http://dx.doi.org/10.15425/redepub.33.2014.01

Universidad de los Andes

Facultad de Derecho

Revista de Derecho Público N. ${ }^{\circ} 33$

Julio - Diciembre de 2014. ISSN 1909-7778 


\title{
Reparación administrativa, eficacia de la acción de tutela y víctimas del conflicto armado
}

\section{Resumen}

El artículo presenta las conclusiones de una investigación acerca de la efectividad de los procedimientos administrativos y judiciales que deben adelantar las víctimas del conflicto armado colombiano para lograr la reparación administrativa y las ayudas humanitarias consagradas en la Ley 1448 de 2011 y el Decreto 3990 de 2007. Para llegar a estas conclusiones se estudiaron 23 casos de víctimas asesoradas legalmente por el Consultorio Jurídico de la Universidad de los Andes. En el análisis de estos casos se tuvieron en cuenta tres variables: (i) el tiempo de respuesta y la calidad y coherencia de estas por parte de las entidades estatales a las víctimas; (ii) los procedimientos administrativos que deben seguir las víctimas; y (iii) la efectividad de la acción de tutela para proteger los derechos fundamentales de las víctimas del conflicto armado.

Palabras clave: reparación administrativa, ayudas humanitarias, efectividad de la acción de tutela, incidente de desacato.

\section{Administrative reparation, effectiveness of the action of "tutela" and victims of armed conflict}

\begin{abstract}
This article presents the conclusions of a research about the effectiveness of the administrative and judicial procedures to be followed by Victims of Colombian 's armed conflict to achieve administrative compensation and humanitarian aid enshrined in Colombian Law. To reach these conclusions, 23 cases of victims legally advised by the Legal Clinic of the University of the Andes were studied. For the analysis of these cases were considered three variables: (i) response time, quality and consistency of responses from state agencies to victims, (ii) the administrative procedures to be followed by the victims, and (iii) the effectiveness of the judgments of constitutional judges to protect the fundamental rights of the victims of armed conflict.

Keywords: administrative compensation, humanitarian aid, effectiveness of the judgments of constitutional judges.

\section{Reparação administrativa, eficácia da ação de tutela e vítimas do conflito armado Resumo}

$\mathrm{O}$ artigo apresenta as conclusões de uma pesquisa sobre a efetividade dos procedimentos administrativos e judiciais que as vítimas do conflito armado colombiano devem proceder para conseguir a reparação administrativa e as ajudas humanitárias consagradas na Lei 1448 de 2011 e o Decreto 3990 de 2007. Para chegar a estas conclusões foram estudados 23 casos de vítimas assessoradas legalmente pelo Consultório Jurídico da Universidad de los Andes. Na análise destes casos foram levadas em conta três variáveis: (i) o tempo de resposta e a qualidade e coerência destas por parte das entidades estatais às vítimas; (ii) os procedimentos administrativos que devem seguir as vítimas; e (iii) a efetividade da ação de tutela para proteger os direitos fundamentais das vítimas do conflito armado.
\end{abstract}

Palavras-chave: reparação administrativa, ajudas humanitárias, efetividade da ação de tutela, incidente de desacato. 


\title{
Reparación administrativa, eficacia de la acción de tutela y víctimas del conflicto armado*
}

\author{
Pablo Ernesto Medrano Moreno**
}

\section{SUMARIO}

Introducción - I. MARCO NORMATIVO DE LA REPARACIÓN ADMINISTRATIVA DE LAS VÍCTIMAS DEL CONFLICTO ARMADO COLOMBIANO - A. Procedimiento de reparación administrativa de la Ley 1448 de 2011 - B. Ayuda humanitaria - 1. Ayuda humanitaria para víctimas de hechos diferentes al desplazamiento forzado - 2. Ayuda humanitaria para las víctimas del desplazamiento forzado - C. Indemnización a cargo de la cuenta del Fosyga a las víctimas de atentados terroristas - D. Análisis formal de los procedimientos administrativos que deben adelantar las víctimas del conflicto armado colombiano - 1. Reparación administrativa - 2. Ayudas humanitarias - 3. Indemnización a cargo de la cuenta del Fosyga, a las víctimas de atentados terroristas - II. LA REPARACIÓN EN LA PRÁCTICA: ESTUDIO DE CASOS - A. Los actos administrativos: respuestas del Estado a las víctimas - 1. Unidad para las Víctimas - 1.1. Solicitud de inclusión en el Ruv - 1.2. Derechos de petición solicitando información sobre el trámite de la inclusión en el Ruv o la solicitud de indemnización administrativa - 1.3. Solicitud de entrega o priorización ayuda humanitaria - 2. Unión Temporal Nuevo Fosyga - 2.1. Solicitud de indemnización Decreto 3990 de 2007 - 2.2. Derechos de petición solicitando información sobre el trámite de reconocimiento y entrega de la indemnización del Decreto 3990 de 2007 - B. Procedimientos administrativos: los tortuosos senderos de las víctimas - 1. Inclusión en el Ruv y solicitud de pago de la indemnización administrativa - 2. Ayudas humanitarias - 3. Solicitud de indemnización Decreto 3990 de 2007 - C. La acción de tutela: la esperanza de las víctimas - 1. Protección formal del derecho - 1.1. Hechos que motivaron la interposición de las acciones de tutela - 1.2. Fallos de tutela - 1.3. Coherencia de las sentencias - 2. Cumplimiento de la administración a los fallos de tutela y a los requerimientos de los jueces - 3. Diligencia del juzgado para adelantar el incidente de desacato tendiente al cumplimiento del fallo judicial - 3.1. Apertura del incidente de desacato - 3.2. Actitud del juez frente al incumplimiento de la entidad a su requerimiento - 3.3. Duración de un incidente de desacato - III. LA REPARACIÓN: DE LA TEORÍA A LA REALIDAD - A. Reparación administrativa - B. Ayuda humanitaria - C. Indemnización del Decreto 3990 de 2007 - D. La acción de tutela - IV. EL TIEMPO DE LAS REPARACIONES: PROBLEMAS Y POSIBLES SOLUCIONES - A. Ventajas y limitaciones del estudio de casos - B. Principales problemas y sus posibles causas - C. Posibles soluciones - 1 . Frente a la Unidad para las Víctimas - 2. Frente a la Unión Temporal Nuevo Fosyga - 3. Procesos de tutela - Referencias.

Cómo citar este artículo: Medrano Moreno, P. E. (Diciembre, 2014). Reparación administrativa, eficacia de la acción de tutela y víctimas del conflicto armado. Revista de Derecho Público, 33. Universidad de los Andes (Colombia).

** Abogado especialista en derecho constitucional de la Universidad Nacional de Colombia. Estudiante del programa de Maestría en Derecho de la misma Universidad. Coordinador del Área de Derecho Público del Consultorio Jurídico de la Universidad de los Andes. Correo: pe.medrano31@uniandes.edu.co 
Introducción

Este artículo de reflexión presenta, desde una perspectiva analítica y crítica, los resultados de una investigación acerca de la efectividad de los procedimientos administrativos y judiciales para lograr la reparación administrativa de las víctimas del conflicto armado colombiano. Concretamente, el objetivo planteado al inicio de la investigación era determinar si los trámites administrativos que deben adelantar las víctimas (usuarios del Consultorio Jurídico de la Universidad de los Andes) ante la Unidad Administrativa Especial de Atención y Reparación Integral a Víctimas (en adelante Unidad para las Víctimas o Unidad) son idóneos, rápidos y eficaces, como lo deben ser, de acuerdo con lo establecido en la Ley 1448 de 2011 y sus decretos reglamentarios. Igualmente, se planteó la necesidad de estudiar el procedimiento administrativo tendiente a reparar (por medio de la entrega de una indemnización especial) a las víctimas de eventos terroristas, trámite que se adelanta ante la Unión Temporal Nuevo Fosyga y el Consorcio SAYP, y que se encuentra reglamentado por el Decreto 3990 de 2007. Adicional al estudio de la efectividad de estos trámites administrativos, la acción de tutela, como medio para la protección de los derechos fundamentales de las víctimas, fue también objeto de análisis para determinar si es eficaz y eficiente para garantizar los derechos de las víctimas que han sido desconocidos por las entidades públicas.

La investigación partió de la siguiente hipótesis: los procedimientos administrativos que las víctimas del conflicto armado tienen que adelantar ante la Unidad para las Víctimas y la Unión Temporal Nuevo Fosyga son un obstáculo para lograr la reparación, por lo que generalmente tienen que acudir a la acción de tutela para buscar la satisfacción de sus derechos por vía judicial. Las causas que, se intuía, podían hacer ineficaces estos procedimientos administrativos eran principalmente dos: la demora en las respuestas a las solicitudes de indemnización administrativa y la falta de recursos económicos para entregar las indemnizaciones pecuniarias y ayudas humanitarias. Para confirmar esta hipótesis se siguió la metodología que a continuación se explica.

La investigación se realizó en tres etapas, que corresponden a las tres primeras partes de las cuatro que componen este escrito. En primer lugar, se analizaron los procedimientos establecidos por la Ley 1448 de 2011 y los decretos 4800 de 2011 y 3990 de 2007, particularmente, se estudiaron los procedimientos tendientes a lograr tres finalidades: la reparación administrativa, la entrega de las ayudas humanitarias y la indemnización para víctimas de atentados terroristas. El objetivo de esta etapa era establecer el marco normativo de la investigación. Para realizar el análisis formal de estas normas jurídicas se tomaron en cuenta los siguientes criterios: (i) claridad de las normas; (ii) divulgación y publicidad de las normas; (iii) requisitos formales que deben cumplir las víctimas para acceder a los beneficios; (iv) plazos que las víctimas tienen para presentar sus solicitudes; y (v) términos que tienen las entidades para resolver las solicitudes. 
En la segunda etapa se realizó un estudio de casos con el fin de determinar la eficacia de los mecanismos arriba enunciados. El insumo fueron los casos adelantados por el grupo de atención a víctimas del conflicto armado, del Área de Derecho Público del Consultorio Jurídico de la Universidad de los Andes, a partir del segundo semestre de 2011 y hasta el segundo semestre de 2013. De ese modo, se estudiaron en total 23 casos que incluyen diferentes hechos victimizantes. Para el análisis de estos casos se tuvieron en cuenta tres variables: (i) los actos administrativos; (ii) los procedimientos administrativos; y (iii) los procesos de tutela. En la primera se analizó el tiempo y la calidad de las respuestas de la administración a las solicitudes de las víctimas. Para esto, se tomaron en cuenta los siguientes criterios: (i) tiempo de respuesta a las solicitudes de las víctimas por parte de la administración; (ii) coherencia de las respuestas con las solicitudes; y (iii) coherencia de los actos administrativos de las entidades con las normas jurídicas aplicables a cada caso. La segunda variable buscó analizar el proceso administrativo en su conjunto, a partir de los siguientes criterios: (i) facilidad para realizar las declaraciones como víctimas del conflicto o radicar las demás solicitudes; (ii) información oportuna por parte de los funcionarios sobre el procedimiento administrativo; y (iii) facilidad para la radicación de correspondencia y notificación de los actos administrativos. La tercera y última variable analizó el proceso de tutela, es decir, la efectividad de la acción de tutela para proteger los derechos de las víctimas; aquí se hizo uso de tres criterios: (i) protección formal del derecho; (ii) cumplimiento de la administración a los fallos de tutela y a los requerimientos de los jueces; y (iii) diligencia del juzgado para adelantar el incidente de desacato tendiente al cumplimiento del fallo judicial. Así, el primer criterio se centró en el análisis formal del contenido de los fallos de tutela, mientras que los otros dos se enfocaron en la efectividad de los fallos de tutela para proteger los derechos de las víctimas, por lo que el eje del análisis fue el trámite del incidente de desacato.

En la tercera parte se exponen las conclusiones que arrojó la investigación frente al trabajo tanto de las autoridades administrativas como judiciales en la protección de los derechos de las víctimas del conflicto armado colombiano, especialmente, de la reparación por vía administrativa. Es decir, la ineficacia de los procedimientos administrativos para cumplir los fines de la reparación, así como la inoperancia de la acción de tutela para proteger los derechos de las víctimas.

Finalmente, en la cuarta parte de este escrito se realiza un análisis crítico de estos resultados; igualmente, se plantean las posibles causas estructurales que originan las fallas de la reparación administrativa, así como las "reparaciones" que se deberían implementar para hacer efectivas las normas sobre la reparación y cumplir así con los objetivos planteados por la Ley 1448 de 2011. De ese modo, se concluye que además de la demora en las respuestas a las solicitudes de indemnización administrativa y la falta de recursos económicos para entregar las indemnizaciones pecuniarias, existen otros problemas que deben ser solucionados y, además, que contrario a lo intuido en la hipótesis 
inicial de la investigación, la acción de tutela no siempre es un mecanismo eficiente para la satisfacción de los derechos de las víctimas del conflicto armado colombiano.

\section{MARCO NORMATIVO DE LA REPARACIÓN ADMINISTRATIVA DE LAS VÍCTIMAS DEL CONFLICTO ARMADO COLOMBIANO}

A continuación se exponen los trámites que deben adelantar las víctimas del conflicto armado, tendientes a obtener la reparación por vía administrativa, la entrega de las ayudas humanitarias y la indemnización que otorga el Fosyga a las víctimas de atentados terroristas, así como los principios que rigen dicha reparación. Para esto, primero se describen brevemente los mecanismos de reparación y ayuda antes señalados, y posteriormente se analizan los procedimientos administrativos establecidos para acceder a estos.

\section{A. Procedimiento de reparación administrativa de la Ley 1448 de 2011}

El proceso de reparación establecido en la Ley 1448 de 2011 se enmarca dentro de un contexto de justicia transicional "sin transición" (Uprimny, 2006), es decir, un proceso de reparación en medio de un conflicto armado. Proceso que busca superar las falencias del Decreto 1290 de 2008 y la Ley 418 de 1997, normas sobre reparación vigentes antes de la nueva Ley de Víctimas y Restitución de Tierras, y lograr una reparación más expedita de las víctimas del con- flicto armado. Por eso, como principios orientadores de la reparación, la Ley 1448 establece la dignidad de las víctimas, la buena fe, el debido proceso, el enfoque diferencial, entre otros.

Concretamente, el Decreto 4800 de 2011 desarrolla el procedimiento administrativo que deben seguir las víctimas para lograr la inclusión en el registro único de víctimas y posterior reparación integral. Procedimiento que puede sintetizarse en los siguientes pasos:

1). La víctima debe realizar una declaración juramentada de los hechos victimizantes ante cualquier entidad del Ministerio Público (procuradurías, personerías o defensorías del pueblo).

2). La Unidad para la Atención y Reparación Integral a las Víctimas (en adelante Unidad para las Víctimas), entidad encargada del Registro Único de Víctimas (RUv), analiza la declaración de la víctima y los documentos que hubiere allegado, con el fin de decidir si otorga o deniega el registro, para lo cual tiene un término de 60 días hábiles.

3). Una vez la víctima se encuentre inscrita en el Ruv puede solicitar ante la Unidad para las Víctimas la reparación administrativa, la cual será entregada atendiendo a los principios de progresividad y gradualidad.

Así las cosas, frente al Decreto 1290 de 2008, el procedimiento establecido en el Decreto 4800 de 2011 reduce los términos para resolver la solicitud de reparación por vía administrativa de 
18 meses a 60 días, igualmente, simplifica el procedimiento.

\section{B. Ayuda humanitaria}

En cuanto a la ayuda humanitaria, el Decreto 4800 de 2011 estableció varias distinciones o clasificaciones, la primera de ellas entre víctimas de hechos diferentes al desplazamiento forzado y víctimas de este hecho; adicionalmente, frente a las víctimas del desplazamiento forzado distingue entre ayuda humanitaria inmediata, de emergencia y de transición. A continuación una breve descripción de cada una de estas categorías y subcategorías.

\section{Ayuda humanitaria para víctimas de hechos diferentes al desplazamiento forzado}

Para las víctimas de hechos diferentes al desplazamiento forzado, los artículos 102 a 105 del Decreto 4800 de 2011 establecen dos tipos de ayudas: una inmediata que se paga dentro de los tres meses siguientes a la ocurrencia de los hechos, y que busca mitigar la situación de vulnerabilidad acentuada a consecuencia de los hechos victimizantes. Esta ayuda cubre los componentes de alimentación, aseo personal, manejo de abastecimientos, utensilios de cocina, atención médica y psicológica de emergencia, transporte de emergencia y alojamiento transitorio. Las entidades territoriales son las responsables de garantizar la entrega de estas ayudas a las víctimas por el término de un mes, término que puede ser prorrogado hasta por un mes adicional en los casos en que la vulnerabilidad derivada del hecho victimizante lo amerite (art. 102).

Por otro lado, la Unidad para las Víctimas suministra, por una sola vez, otra ayuda humanitaria tendiente a mitigar o a impedir la agravación o la extensión de los efectos de los hechos victimizantes (ayuda humanitaria que corresponde a la consagrada en el artículo 49 de la Ley 418 de 1997); el monto de la ayuda depende de la afectación derivada del hecho victimizante y de las circunstancias de tiempo, modo y lugar de este.

\section{Ayuda humanitaria para las víctimas del desplazamiento forzado}

En el caso de las víctimas del desplazamiento forzado, el Decreto 4800 de 2011 tiene como principal novedad la distinción de tres tipos de ayudas humanitarias que se otorgan para suplir necesidades diferentes, están a cargo de entidades distintas y los montos y opciones de prórroga son también diferentes. En seguida se explica brevemente cada una de estas clases de ayudas.

Ayuda humanitaria inmediata: es responsabilidad de las entidades territoriales receptoras de la población víctima de desplazamiento garantizar a esta los componentes de alimentación, artículos de aseo, manejo de abastecimientos, utensilios de cocina y alojamiento transitorio, mientras se realiza el trámite de inscripción en el Ruv (art. 108, Decreto 4800 de 2011).

Ayuda humanitaria de emergencia: está a cargo de la Unidad para las Víctimas, ya sea 
directamente o a través de convenios que se establezcan con organismos nacionales e internacionales con ocasión de la entrega de los componentes de alimentación, artículos de aseo, manejo de abastecimientos, utensilios de cocina y alojamiento transitorio a la población incluida en el Ruv, cuyo hecho victimizante (desplazamiento forzado) haya ocurrido dentro del año previo a la declaración (art. 109, Decreto 4800 de 2011).

Ayuda humanitaria de transición: es responsabilidad de la Unidad para las Víctimas y está destinada a cubrir los componentes de alimentación, artículos de aseo y alojamiento temporal de la población víctima de desplazamiento forzado incluida en el Ruv, cuyo desplazamiento haya ocurrido en un término superior a un año contado a partir de la declaración y que, previo análisis de vulnerabilidad, evidencie la persistencia de carencias en los componentes de alimentación y alojamiento como consecuencia del desplazamiento forzado (art. 112, Decreto 4800 de 2011).

\section{Indemnización a cargo de la cuenta del Fosyga, a las víctimas de atentados terroristas}

El Decreto 3990 de 2007 reglamenta la Subcuenta del Seguro de Riesgos Catastróficos y Accidentes del Tránsito del Fondo de Solidaridad y Garantía, Fosyga. Esta norma establece una especie de subsidio o indemnización a favor de las víctimas de atentados terroristas, y en el artículo $1^{\circ}$ numeral $5^{\circ}$ instituye como beneficiarios de esta a aquellas personas vícti- mas de bombas, minas antipersonales y otros artefactos explosivos; las víctimas de ataques a municipios -el decreto se expidió cuando eran frecuentes las tomas guerrilleras a municipios-; y las víctimas de masacres. El reconocimiento de la condición de víctima, y por tanto de "beneficiario" del subsidio, está a cargo de la Unión Temporal Nuevo Fosyga, responsable de recibir y analizar las solicitudes. Posteriormente, el Consorcio SAYP se encarga de efectuar el pago de la indemnización a las víctimas reconocidas por la Unión Temporal. El plazo que tienen las víctimas para presentar la solicitud es de un año a partir del hecho victimizante.

\section{Análisis formal de los procedimientos administrativos que deben adelantar las víctimas del conflicto armado colombiano}

Con anterioridad se describieron brevemente algunos de los instrumentos que el Estado colombiano ha implementado para reparar a las víctimas del conflicto armado, es decir, la reparación administrativa, la entrega de ayudas humanitarias, y la entrega de una indemnización especial a favor de las víctimas de atentados terroristas. Ahora se analizarán los procedimientos que deben seguir las víctimas para obtener el reconocimiento y entrega de estos medios de reparación y ayuda. El objetivo de este análisis es establecer el nivel de accesibilidad formal de dichos procedimientos administrativos, es decir, los requisitos que formalmente establecen las normas. Posteriormente, en la tercera parte de este escrito, se comparará la accesibilidad formal con la accesibilidad material, para determi- 
nar los obstáculos que en la práctica deben superar las víctimas para lograr el reconocimiento y pago de la reparación administrativa, las ayudas humanitarias y la indemnización del Fosyga.

Para realizar el análisis formal de los procedimientos administrativos se usaron las siguientes variables: (i) claridad de las normas; (ii) divulgación y publicidad de las normas; (iii) requisitos formales que deben cumplir las víctimas para acceder a los beneficios (reparación administrativa, ayuda humanitaria e indemnización del Fosyga); (iv) los términos que tienen las víctimas para presentar sus solicitudes; y (v) los términos que tienen las entidades para resolver las solicitudes. Así, con la primera variable se buscó determinar si las leyes o decretos están escritos de forma clara, es decir, si una persona común puede entender el procedimiento que debe seguir. Con la segunda variable se pretendió establecer si existe una adecuada publicidad de las normas por parte de la entidad o entidades responsables de su cumplimiento, por ejemplo, si es fácil para las víctimas acceder a las normas. La tercera variable indagó sobre las exigencias que deben cumplir las víctimas, es decir, los documentos que deben aportar, si es posible allegar fotocopias, la necesidad de diligenciar formatos, presentar declaraciones ante varias entidades, etc. La cuarta variable se centró en el plazo que tienen las víctimas para presentar sus solicitudes (términos de caducidad). Finalmente, la quinta variable buscó identificar el tiempo que deben esperar las víctimas para obtener una respuesta de fondo a su solicitud.

\section{Reparación administrativa}

La reparación administrativa se encuentra regulada en la Ley 1448 de 2011 y desarrollada en el Decreto 4800 de 2011, normas que fijan un procedimiento claro. Así, el Decreto 4800 establece que las víctimas, para acreditar tal condición y solicitar su inscripción en el ruv, simplemente deben acudir a una dependencia del Ministerio Público a rendir su declaración detallada de los hechos víctimizantes, indicando las circunstancias de tiempo, modo y lugar, y en sesenta días obtendrán una respuesta. Si la víctima quiere allegar algún tipo de certificado, documentos o pruebas de los hechos, puede hacerlo pero no es algo que se le exija. Sobre el procedimiento que deben adelantar las víctimas existen varias publicaciones tipo cartilla, generalmente escritas en un lenguaje sencillo, por lo que puede hablarse de una adecuada publicación y divulgación.

Una vez realizada la declaración, la Unidad para las Víctimas debe valorar la solicitud, para lo cual el Decreto 4800 le otorga amplias facultades oficiosas, como la de solicitar pruebas a diferentes entidades y revisar bases de datos (art. $37)$, solicitar el traslado de pruebas de procesos penales o administrativos (art. 38), entre otras. Finalmente, decide si incluye o no al solicitante en el Ruv. En ambos casos, los actos administrativos deben contener los motivos por los cuales la Unidad para las Víctimas llegó a dicha decisión, notificar el acto e informar los recursos que proceden (arts. 41 y 42 ). 
Frente a los recursos contra los actos que niegan el registro, el artículo 157 de la Ley 1448 de 2011 establece lo siguiente:

Contra la decisión que deniegue el registro, el solicitante podrá interponer el recurso de reposición ante el funcionario que tomó la decisión dentro de los cinco (5) días siguientes a la notificación de la decisión. El solicitante podrá interponer el recurso de apelación ante el Director de la Unidad Administrativa Especial de Atención y Reparación Integral a las Víctimas de que trata la presente Ley contra la decisión que resuelve el recurso de reposición dentro de los cinco (5) días siguientes a la notificación de esta decisión.

Al respecto se pueden hacer los siguientes comentarios: en primer lugar, a diferencia del trámite normal de los recursos en materia administrativa, aquí se permite interponer los recursos de reposición y apelación de manera autónoma: el primero ante el funcionario que adoptó la decisión, y después, una vez notificada la decisión que resuelve la reposición, el de apelación ante el director de la Unidad para las Víctimas, lo cual en principio es garantista pues da más tiempo para interponer la apelación, pero también implica un mayor tiempo en comparación con la generalidad de los procedimientos administrativos, en los que una vez resuelta la reposición automáticamente se remite el expediente al superior para decidir la apelación; en segundo lugar, la norma se ubica en el contexto del anterior Código Administrativo (Decreto 01 de 1984), por lo que el término para interponer los recursos es de cinco (5) días, mientras que el nuevo Código de Procedimiento Administrativo y de lo
Contencioso Administrativo (Ley 1437 de 2011) establece un término de diez (10) días, que es mucho más garantista teniendo en cuenta que muchas de las víctimas acuden a los consultorios jurídicos y, en consecuencia, se pierden varios días mientras llegan al consultorio y el caso es estudiado y asignado a un estudiante; finalmente, la norma convierte a la reposición en un recurso obligatorio.

En cuanto al término que tienen las víctimas para realizar la inscripción en el Ruv, el Decreto 4800 establece varias situaciones: (i) si el hecho victimizante sucedió antes del 10 de junio de 2011, el plazo máximo para declarar será de cuatro años después de esta fecha, salvo los casos de desplazamiento forzado; (ii) si el hecho victimizante ocurrió después del 10 de junio de 2011, el término máximo para declarar es de dos años a partir de la fecha de la ocurrencia del hecho; (iii) en el caso del desplazamiento forzado ocurrido antes del 10 de junio de 2011, la persona tiene dos años a partir de esa fecha para realizar la declaración.

Finalmente, el término que se le otorga a la Unidad para las Víctimas para resolver de fondo la solicitud de inscripción en el Ruv es relativamente corto: sesenta días hábiles, lo cual constituye un gran avance frente a los dieciocho meses que establecía el Decreto 1290 de 2008.

Ahora, el hecho de que se incluya al solicitante en el Ruv no implica que automáticamente se le vaya a hacer la entrega efectiva de la respectiva indemnización, pues de acuerdo con el artículo 151 del Decreto 4800 de 2011, este debe soli- 
citarla una vez esté registrado. Entrega que no está sujeta al orden de radicación de las solicitudes, sino a los criterios contemplados en los principios de progresividad y gradualidad para una reparación efectiva y eficaz, es decir, la Unidad para las Víctimas debe tener en cuenta, entre otros criterios, la naturaleza del hecho victimizante, el daño causado, el nivel de vulnerabilidad basado en un enfoque etario del grupo familiar, las características del núcleo familiar y la situación de discapacidad de alguno de los miembros del hogar, o la estrategia de intervención territorial integral.

\section{Ayudas humanitarias}

Como se señaló con anterioridad, el Decreto 4800 de 2011 establece varias clases de ayudas humanitarias, lo cual, si bien responde a las diferentes necesidades de las víctimas en razón del hecho victimizante y del tiempo transcurrido entre el hecho y la solicitud de ayuda, puede generar cierto grado de confusión entre las víctimas. En cuanto al procedimiento y requisitos para solicitarlas, en términos generales, $y$ al igual que en el caso de la reparación, existe una amplia divulgación y publicidad.

Los requisitos formales para la entrega dependen de la clasificación de estas ayudas. La ayuda inmediata por hechos diferentes al desplazamiento no requiere ninguna formalidad, incluso se entrega sin necesidad de estar inscrito en el ruv. La ayuda de emergencia, que está a cargo de la Unidad para las Víctimas, sí exige que la persona realice la declaración de los hechos o se encuentre relacionada en un censo de vícti- mas y, además, que allegue fotocopia del documento de identidad y copias de los registros civiles de nacimiento o defunción, según el caso, para efectos de acreditar el parentesco en los casos de homicidio o desaparición forzada.

Adicionalmente, el numeral $5^{\circ}$ del artículo $1^{\circ}$ de la Resolución 2349 del 28 de diciembre de 2012 de la Unidad para las Víctimas, determina que solo es posible la entrega de esta ayuda en aquellos casos en los que se rinda la declaración o se levante el censo de víctimas en un periodo no mayor a un año de ocurrido el hecho victimizante, lo cual puede entenderse como un término de caducidad que ni la Ley 1448 de 2011 ni el Decreto 4800 de 2011 establecen para la entrega de las ayudas, por lo que la Unidad para las Víctimas expidió una resolución modificando la norma que debía reglamentar.

No se encontró un término para que la entidad decida la solicitud y entregue la ayuda. El numeral $6^{\circ}$ del artículo $6^{\circ}$ de la Resolución 2349 de 2012 simplemente señala que "[l]os montos de la ayuda humanitaria serán entregados de acuerdo con la afectación derivada del hecho victimizante".

En cuanto a la ayuda humanitaria para las víctimas del desplazamiento forzado, como antes se indicó, existen tres clases: la ayuda inmediata que no requiere mayor formalismo; la ayuda de emergencia, en la cual el único requisito es estar incluido en el Ruv y presentar la solicitud ante la Unidad para las Víctimas, se entrega por tres meses (art. 7, Resolución 3069 de 2010 de Acción Social), y en caso de ser necesario, 
la víctima debe, transcurrido ese término, realizar nuevamente una solicitud de prórroga ante la Unidad para las Víctimas; y la ayuda de transición, que además de la inscripción en el Ruv requiere acreditar la persistencia de carencias en los componentes de alimentación y alojamiento como consecuencia del desplazamiento forzado, por lo que los solicitantes deben allegar los documentos que acrediten su situación de vulnerabilidad, como pruebas de enfermedades crónicas, personas en condición de discapacidad, existencia en el núcleo familiar de adultos mayores o niños, etc.

Si bien no existe un término de caducidad para solicitar estas ayudas, dependiendo el lapso de tiempo entre la ocurrencia de los hechos que generaron el desplazamiento y la solicitud se determina qué tipo de ayuda le corresponde recibir a la víctima. De ese modo, la ayuda inmediata se entrega a las víctimas al momento de la ocurrencia de los hechos, la ayuda de emergencia procede cuando el desplazamiento forzado haya ocurrido dentro del año previo a la declaración como víctima, y la ayuda de transición se entrega cuando el desplazamiento haya ocurrido en un término superior a un año contado a partir de la declaración y el análisis de vulnerabilidad evidencie la persistencia de carencias en los componentes de alimentación y alojamiento como consecuencia del desplazamiento forzado.

En el caso de esta última ayuda, cuando el desplazamiento forzado haya ocurrido en un término igual o superior a diez años antes de la solicitud, se entiende que la situación de emergencia no está directamente relacionada con el desplazamiento forzado, razón por la cual las solicitudes deberán ser remitidas a la oferta disponible para la estabilización socioeconómica, salvo en casos de extrema urgencia y vulnerabilidad manifiesta derivada de aspectos relacionados con grupo etario, situación de discapacidad y composición del hogar (art. 112, Decreto 4800 de 2011). Finalmente, no se encontró un término para responder las solicitudes o para entregar la respectiva ayuda, simplemente algunos criterios de priorización.

\section{Indemnización a cargo de la cuenta del Fosyga, a las víctimas de atentados terroristas}

La indemnización a cargo de la cuenta del Fosyga está regulada principalmente por el Decreto 3990 de 2007 y la Resolución 1915 de 2008 del Ministerio de la Protección Social, normas que no son para nada claras, pues están redactadas en un lenguaje muy técnico. Así por ejemplo, el Decreto 3990 además de la indemnización a las víctimas de atentados terroristas también regula otros temas, como el Seguro Obligatorio de Accidentes de Tránsito (SOAT), los subsidios por catástrofes naturales, el recobro por parte de las entidades de salud, entre otros. Por lo tanto, combina distintos trámites, está dirigido a varios destinatarios y no establece un procedimiento claro y preciso para las víctimas de atentados terroristas.

Tanto las normas como los formatos que deben diligenciar las víctimas no son de fácil consulta o adquisición, tampoco existe una debida 
publicidad sobre este beneficio y, además, son varios los requisitos que se exigen, entre otros: certificación original expedida por un personero o alcalde municipal que constate el atentado, censo de víctimas elaborado por la personería, formulario diligenciado por el solicitante, historia clínica, certificado original de la junta de calificación de la pérdida de capacidad laboral (que tiene un costo de un salario diario mínimo legal vigente), entre otros (art. 4, Decreto 3990 de 2007).

Por otra parte, el término que tiene la víctima para presentar la solicitud junto con todos los documentos exigidos es de un año a partir de la ocurrencia del atentado terrorista, pero no se encontró un término para que la entidad responda la solicitud y realice el pago de la indemnización.

Tabla 1: Análisis formal de los procedimientos administrativos

\begin{tabular}{|c|c|c|c|c|c|}
\hline \multicolumn{6}{|c|}{ Indemnización administrativa } \\
\hline $\begin{array}{c}\text { Claridad de las } \\
\text { normas }\end{array}$ & $\begin{array}{l}\text { Publicidad y } \\
\text { divulgación }\end{array}$ & $\begin{array}{l}\text { Requisitos } \\
\text { formales }\end{array}$ & \multicolumn{2}{|c|}{ Término para presentar solicitud } & $\begin{array}{c}\text { Término de la entidad } \\
\text { para responder }\end{array}$ \\
\hline $\begin{array}{l}\text { Las normas } \\
\text { son claras. }\end{array}$ & $\begin{array}{l}\text { Adecuada publi- } \\
\text { cidad y divulga- } \\
\text { ción del proce- } \\
\text { dimiento. }\end{array}$ & \begin{tabular}{|l|l} 
Para la declara- & ( \\
ción no se exige & $\mathrm{t}$ \\
allegar ningún & $\mathrm{n}$ \\
documento. & $\mathrm{a}$ \\
& $\mathrm{c}$ \\
& ( \\
& $\mathrm{c}$ \\
& $\mathrm{t}$ \\
& \\
& \\
& $\mathrm{c}$ \\
& $\mathrm{c}$ \\
& $\mathrm{a}$ \\
& $\mathrm{c}$
\end{tabular} & \multicolumn{2}{|c|}{$\begin{array}{l}\text { (i) si el hecho victimizante sucedió an- } \\
\text { tes del } 10 \text { de junio de } 2011 \text {, el plazo } \\
\text { máximo para declarar será de cuatro } \\
\text { años después de esta fecha, salvo los } \\
\text { casos de desplazamiento forzado; } \\
\text { (ii) si el hecho victimizante ocurrió } \\
\text { después del } 10 \text { de junio de } 2011 \text {, el } \\
\text { término máximo para declarar es de } \\
\text { dos años a partir de la fecha de la } \\
\text { ocurrencia del hecho; (iii) en el caso } \\
\text { del desplazamiento forzado ocurrido } \\
\text { antes del } 10 \text { de junio de } 2011 \text {, la per- } \\
\text { sona tiene dos años para realizar la } \\
\text { declaración a partir de esa fecha. }\end{array}$} & $\begin{array}{l}\text { Sesenta días hábiles } \\
\text { para decidir la solici- } \\
\text { tud de inscripción en } \\
\text { el Ruv. Para la entrega } \\
\text { de la indemnización } \\
\text { no hay término fijo, } \\
\text { sino criterios genera- } \\
\text { les para establecer el } \\
\text { orden de entrega. }\end{array}$ \\
\hline \multicolumn{6}{|c|}{ Ayudas humanitarias } \\
\hline $\begin{array}{c}\text { Claridad de las } \\
\text { normas }\end{array}$ & $\begin{array}{l}\text { Publicidad y } \\
\text { divulgación }\end{array}$ & $\begin{array}{l}\text { Requisitos } \\
\text { formales }\end{array}$ & $\begin{array}{l}\text { Término para presen- } \\
\text { tar solicitud }\end{array}$ & \multicolumn{2}{|c|}{$\begin{array}{l}\text { Término de la entidad para } \\
\text { responder }\end{array}$} \\
\hline $\begin{array}{l}\text { Al establecer } \\
\text { d if e r e n t e s } \\
\text { clases de ayu- } \\
\text { das las normas } \\
\text { pueden llegar } \\
\text { a ser confusas } \\
\text { para las vícti- } \\
\text { mas. }\end{array}$ & $\begin{array}{l}\text { Adecuada pu- } \\
\text { blicación y di- } \\
\text { vulgación del } \\
\text { procedimiento, } \\
\text { aunque gene- } \\
\text { ralmente no se } \\
\text { explican detalla- } \\
\text { damente las di- } \\
\text { ferentes clases } \\
\text { de ayudas. }\end{array}$ & $\begin{array}{l}\text { Para las ayudas de } \\
\text { emergencia y tran- } \\
\text { sición estar inscrito } \\
\text { en el RuV. Adicio- } \\
\text { nalmente, para } \\
\text { la ayuda de tran- } \\
\text { sición, acreditar la } \\
\text { condición de vul- } \\
\text { nerabilidad. }\end{array}$ & \begin{tabular}{|l} 
No existe un térmi- \\
no establecido para \\
radicar la solicitud, \\
pero se entiende que \\
después de diez años \\
del desplazamiento la \\
condición de vulnera- \\
bilidad que justifica \\
las ayudas ya fue su- \\
perada.
\end{tabular} & \multicolumn{2}{|c|}{$\begin{array}{l}\text { No hay una norma expresa que es- } \\
\text { tablezca un término de respuesta } \\
\text { por parte de las entidades. }\end{array}$} \\
\hline
\end{tabular}




\begin{tabular}{|c|c|c|c|c|}
\hline \multicolumn{5}{|c|}{ Indemnización a cargo de la cuenta del Fosyga } \\
\hline $\begin{array}{c}\text { Claridad de las } \\
\text { normas }\end{array}$ & $\begin{array}{l}\text { Publicidad y } \\
\text { divulgación }\end{array}$ & $\begin{array}{l}\text { Requisitos } \\
\text { formales }\end{array}$ & $\begin{array}{c}\text { Término para } \\
\text { presentar solicitud }\end{array}$ & $\begin{array}{l}\text { Término de la entidad para } \\
\text { responder }\end{array}$ \\
\hline $\begin{array}{l}\text { Las normas } \\
\text { no son claras, } \\
\text { tienen un len- } \\
\text { guaje muy téc- } \\
\text { nico y en una } \\
\text { sola norma se } \\
\text { regulan varios } \\
\text { aspectos dife- } \\
\text { rentes. }\end{array}$ & $\begin{array}{l}\text { NO existe una } \\
\text { adecuada di- } \\
\text { vulgación y } \\
\text { publicidad de } \\
\text { las normas que } \\
\text { regulan este } \\
\text { trámite. }\end{array}$ & $\begin{array}{l}\text { NO se aceptan co- } \\
\text { pias, solo docu- } \\
\text { mentos originales, } \\
\text { salvo imposibilidad } \\
\text { de obtenerlos. Se } \\
\text { deben adjuntar va- } \\
\text { rias certificaciones } \\
\text { y formatos comple- } \\
\text { jos. }\end{array}$ & $\begin{array}{l}\text { Un año a partir del } \\
\text { evento terrorista. }\end{array}$ & $\begin{array}{l}\text { No hay una norma que determine } \\
\text { el término para responder la solici- } \\
\text { tud o entregar la indemnización. }\end{array}$ \\
\hline
\end{tabular}

\section{LA REPARACIÓN EN LA PRÁCTICA: ESTUDIO DE CASOS}

En la primera parte de este escrito se presentó el análisis formal de las normas que regulan los procedimientos para la inscripción en el Ruv y el pago de la indemnización administrativa, la solicitud de ayudas humanitarias y la solicitud de pago de la indemnización a cargo de la cuenta del Fosyga. Corresponde ahora examinar la aplicación que los funcionarios administrativos dan a dichas normas. Para esto, el insumo fueron los casos adelantados por el grupo de atención a víctimas del conflicto armado, del Área de Derecho Público del Consultorio Jurídico de la Universidad de los Andes. Se estudiaron en total 23 casos que incluyen diferentes hechos víctimizantes, teniendo en cuenta tres variables: (i) los actos administrativos; (ii) los procedimientos administrativos; y (iii) los procesos de tutela.

En la primera variable se usaron los siguientes criterios: (i) tiempo de respuesta a las solicitudes de las víctimas por parte de la administración; (ii) coherencia de las respuestas con las solicitudes; y (iii) coherencia de los actos admi- nistrativos de las entidades con las normas jurídicas aplicables al caso. En la segunda variable los criterios fueron: (i) facilidad para realizar las declaraciones como víctimas del conflicto o radicar las demás solicitudes; (ii) información oportuna por parte de los funcionarios sobre el procedimiento administrativo; y (iii) facilidad para la radicación de correspondencia y notificación de los actos administrativos. En la tercera variable, que analiza el proceso de tutela, se aplicaron tres criterios: (i) protección formal del derecho; (ii) cumplimiento de la administración a los fallos de tutela y a los requerimientos de los jueces; y (iii) diligencia del juzgado para adelantar el incidente de desacato tendiente al cumplimiento del fallo judicial. A continuación se muestran los resultados del estudio de casos, resultados que serán objeto de un análisis crítico en la cuarta parte de este escrito.

\section{A. Los actos administrativos: respuestas del Estado a las víctimas}

Dentro de los 23 casos analizados se presentaron varias solicitudes dirigidas a distintas entidades y con pretensiones diferentes, por lo que para el análisis de los datos debieron clasificar- 
se por entidades y por solicitudes, así: (i) Unidad para las Víctimas: a) solicitud inclusión en el Ruv; b) derecho de petición solicitando información sobre el trámite de inclusión en el Ruv o solicitando el pago de la indemnización administrativa; c) solicitud entrega ayuda humanitaria y solicitud priorización entrega ayuda humanitaria; (ii) Unión Temporal Nuevo Fosyga: a) solicitud de pago de la indemnización, $y$ b) derecho de petición solicitando información sobre el estado del trámite.

\section{Unidad para las Víctimas}

\subsection{Solicitud de inclusión en el RUV}

De los 23 casos estudiados, en 14 de ellos ya se había presentado la solicitud de reparación por vía administrativa bajo la vigencia del Decreto 1290 de 2008, por lo que de acuerdo con el artículo 155 de la Ley 1448 de 2011 se entendían como solicitudes de inclusión en el Ruv. Según el procedimiento establecido en dicha norma era procedente que la Unidad para las Víctimas las resolviera de oficio dentro de los sesenta días siguientes a la vigencia de la ley, sin embargo, solo en 4 de esos 14 casos la Unidad para las Víctimas procedió a incluir a las víctimas en el RUV y, días después, a pagar la indemnización. En los 9 restantes los interesados debieron pedir a la Unidad para las Víctimas que emitiera una respuesta al respecto, que consistió en que las víctimas debían allegar nuevamente los documentos y el comprobante de radicado de la solicitud, pues al parecer se habían extraviado, es decir, tuvieron que iniciar nuevamente todo el trámite de acuerdo con la Ley 1448 de 2011, esto es: hacer la declaración y esperar a la respuesta sobre inclusión en el Ruv. Hecha esta precisión, a continuación se señalan las estadísticas de los casos estudiados.

1.1.1. Tiempo de respuesta a la solicitud

Tabla 2. Tiempo de respuesta a las solicitudes de inclusión en el Ruv

\begin{tabular}{|c|c|c|c|}
\hline $\begin{array}{c}\text { Número de } \\
\text { solicitudes }\end{array}$ & $\begin{array}{c}\text { Respuestas } \\
\text { oportunas } \\
\text { (60 días) }\end{array}$ & $\begin{array}{c}\text { Respues- } \\
\text { tas extem- } \\
\text { poráneas }\end{array}$ & $\begin{array}{c}\text { Tiempo } \\
\text { promedio de } \\
\text { respuesta }\end{array}$ \\
\hline 19 & 7 & 12 & 5 meses \\
\hline $100 \%$ & $36,8 \%$ & $63,2 \%$ & \\
\hline
\end{tabular}

1.1.2. Coherencia de las respuestas con las solicitudes

Aquí se analizó si las respuestas a las solicitudes de inclusión en el Ruv eran coherentes con los supuestos fácticos del solicitante, pues muchas veces se reconocía la calidad de víctima pero por un hecho diferente, o no se indicaba por qué hecho victimizante se incluía. Así, de los 19 casos, 14 eran coherentes con la solicitud, y en los otros 5 se incurrió en los siguientes errores: no se indicó el hecho victimizante (2 casos), se indicaba un hecho diferente (2 casos), la resolución presentaba errores al identificar al solicitante: cambio de nombre (1 caso).

\subsubsection{Coherencia de las respuestas con las normas jurídicas aplicables}

Esta variable buscaba establecer si los actos que resolvían la solicitud de inclusión en el Ruv, particularmente los que la negaban, estaban correctamente fundamentados en las normas 
jurídicas aplicables. En total se analizaron 10 casos en los que se negó la inclusión, en 8 de los cuales obedeció a una errada interpretación de las normas. Los errores más frecuentes son los siguientes:

Tabla 3: Errores de las resoluciones que niegan la inclusión en el Ruv

\begin{tabular}{|l|l|c|}
\hline \multicolumn{1}{|c|}{$\begin{array}{l}\text { Motivo negación inscripción en } \\
\text { el RUv }\end{array}$} & \multicolumn{1}{|c|}{ Error } & $\begin{array}{c}\text { Número de } \\
\text { casos }\end{array}$ \\
\hline $\begin{array}{l}\text { Los hechos NO se relacionan con } \\
\text { el conflicto armado. }\end{array}$ & $\begin{array}{l}\text { El funcionario consideró que una lesión por causa de una mina } \\
\text { antipersonal no era un hecho que se enmarcara dentro del con- } \\
\text { flicto armado. }\end{array}$ & 2 \\
\hline $\begin{array}{l}\text { NO se probó la condición de víc- } \\
\text { tima. }\end{array}$ & $\begin{array}{l}\text { El funcionario no ejerció las funciones oficiosas para decretar las } \\
\text { pruebas que consideraba necesarias, o simplemente negó el re- } \\
\text { gistro porque según el mapa de vulnerabilidad en la zona de los } \\
\text { hechos no había presencia de grupos armados ilegales. }\end{array}$ & \multicolumn{1}{|c|}{4} \\
\hline $\begin{array}{l}\text { El solicitante se encuentra exclui- } \\
\text { do de la definición de víctima por } \\
\text { su pertenencia a grupos armados } \\
\text { ilegales. }\end{array}$ & $\begin{array}{l}\text { En un caso no se tuvo en cuenta que la persona era menor de } \\
\text { edad cuando se vinculó al grupo armado y fue asesinado siendo } \\
\text { también menor de edad. En el otro caso se desconoció que, si } \\
\text { bien la persona había pertenecido a un grupo armado, posterior- } \\
\text { mente se había desmovilizado, y precisamente por haberse des- } \\
\text { movilizado fue ejecutada extrajudicialmente por miembros del } \\
\text { grupo armado ilegal. }\end{array}$ & 2 \\
\hline
\end{tabular}

\subsection{Derechos de petición solicitando información sobre el trámite de la inclusión en el RUV o la solicitud de indemnización administrativa}

En este punto se analizaron los derechos de petición presentados ante la Unidad para las Víctimas que tenían dos objetivos: (i) averiguar por el estado del proceso de inscripción en el Ruv, particularmente en aquellos casos en los que los personeros no habían entregado ninguna constancia a la víctima de haber realizado su declaración; y (ii) derechos de petición para preguntar por la fecha probable del pago de la indemnización administrativa.
1.2.1. Tiempo de respuesta a la solicitud

Tabla 4: Tiempo de respuesta, derechos de petición presentados a la Unidad para las Víctimas

\begin{tabular}{|c|c|c|c|}
\hline $\begin{array}{c}\text { Número } \\
\text { de } \\
\text { solicitudes }\end{array}$ & $\begin{array}{c}\text { Respuestas } \\
\text { oportunas } \\
\text { (15 días) }\end{array}$ & $\begin{array}{c}\text { Respuestas } \\
\text { extem- } \\
\text { poráneas }\end{array}$ & $\begin{array}{c}\text { Promedio } \\
\text { tiempo de } \\
\text { respuesta }\end{array}$ \\
\hline 32 & 9 & 23 & 9 meses \\
\hline $100 \%$ & $39,1 \%$ & $60,9 \%$ & \\
\hline
\end{tabular}

1.2.2. Coherencia de las respuestas con las solicitudes

Frente a los derechos de petición averiguando sobre el procedimiento de inscripción en el RUv, la mayoría de las veces la Unidad para las Vícti- 
mas respondió con la decisión de inclusión o no inclusión en el Ruv (7 casos), en otros contestó que no había información sobre la víctima (4 casos) y exigía allegar la constancia de presentación de la declaración, respuesta incoherente si se tiene en cuenta que en el derecho de petición se informaba que la Personería no había entregado dicha constancia.

En los derechos de petición preguntando en cuánto tiempo se pagaría la indemnización administrativa, puesto que se había reconocido la calidad de víctima (inclusión en el Ruv), se había presentado la solicitud de indemnización y se reiteraba la solicitud, los niveles de incoherencia detectados fueron mayores. Aquí se clasificaron las respuestas en tres grupos: (i) respuestas coherentes incompletas (se informa que la ayuda se entregará de acuerdo con los principios de progresividad y gradualidad, pero no se indica una fecha o plazo probable); (ii) respuestas incoherentes (se informa que ya fue reconocida la calidad de víctima y que debe presentar la solicitud de reparación, se solicita que allegue nueva documentación para el estudio de su caso, se informa que su estudio está en valoración o se informa sobre otro trámite diferente, verbigracia, la solicitud de ayuda humanitaria); y (iii) respuestas contradictorias (se informa que no fue incluido en el Ruv, cuando anteriormente se le había notificado la resolución de inclusión y lo que se estaba preguntando era la fecha del pago de la indemnización).
Tabla 5: Respuestas incoherentes y contradictorias frente a la reparación administrativa

\begin{tabular}{|l|c|}
\hline \multicolumn{1}{|c|}{ Tipo de respuestas } & Número de casos \\
\hline $\begin{array}{l}\text { Respuestas coherentes incomple- } \\
\text { tas }\end{array}$ & 10 \\
\hline Respuestas incoherentes & 9 \\
\hline Respuestas contradictorias & 2 \\
\hline
\end{tabular}

1.2.3. Coherencia de las respuestas con las normas jurídicas aplicables

Esta variable está muy relacionada con la anterior, pues, generalmente, en las respuestas coherentes incompletas se respondía de acuerdo con los principios de gradualidad y progresividad contemplados en la Ley 1448 de 2011, pero no se cumplía con el deber de informar de manera concreta cómo aplican dichos principios al caso específico. Las respuestas incoherentes y las contradictorias se fundamentaban en normas no aplicables al caso.

\subsection{Solicitud de entrega o priorización ayuda humanitaria}

En este punto se analizaron los derechos de petición presentados ante la Unidad para las Víctimas, que tenían dos objetivos: (i) solicitar la entrega de las diferentes clases de ayuda humanitaria; o (ii) solicitar la priorización del turno de entrega de la ayuda humanitaria. Los segundos surgen cuando el turno asignado para la entrega de la ayuda resulta muy lejano para la situación de vulnerabilidad de la víctima, y esta se ve obligada a solicitar que se aplique un enfoque diferencial, y en consecuencia, se le asigne un turno de entrega más cercano. 
1.3.1. Tiempo de respuesta a la solicitud

Tabla 6: Tiempo de respuesta frente a las ayudas humanitarias

\begin{tabular}{|c|c|c|c|}
\hline $\begin{array}{c}\text { Número de } \\
\text { solicitudes }\end{array}$ & $\begin{array}{c}\text { Respuestas } \\
\text { oportunas } \\
\text { (15 días) }^{1}\end{array}$ & $\begin{array}{c}\text { Respuestas } \\
\text { extem- } \\
\text { poráneas }\end{array}$ & $\begin{array}{c}\text { Promedio } \\
\text { tiempo de } \\
\text { respuesta }\end{array}$ \\
\hline 21 & 5 & 16 & 3 meses \\
\hline $100 \%$ & $23,8 \%$ & $76,2 \%$ & \\
\hline
\end{tabular}

1.3.2. Coherencia de las respuestas con las solicitudes

En este caso el análisis se centró en las solicitudes de priorización de turno, que son las que mayores problemas generan, pues requieren de la valoración de los hechos expuestos en la solicitud por parte del funcionario, mientras que en la solicitud de la ayuda humanitaria el funcionario generalmente se limita a verificar que la persona se encuentre inscrita en el Ruv, que no haya recibido antes la ayuda (en el caso de las ayudas por hechos diferentes al desplazamiento) o que no se le haya entregado la ayuda dentro de los tres meses anteriores a la solicitud (en el caso de las ayudas a las víctimas del desplazamiento forzado).
Frente a la solicitud seleccionada se identificó que las respuestas concediendo o negando la prioridad se podían clasificar en tres grupos: (i) la alusión expresa a la situación fáctica de la víctima; (ii) las que no se basaban de manera expresa en la situación fáctica de la víctima; y (iii) las que simplemente asignaban un nuevo turno de entrega, en algunos casos más lejano que el inicialmente otorgado y sin motivar la decisión, como si fuera una petición normal de entrega de ayuda humanitaria sin tener en cuenta que lo que se solicitaba era la prioridad en el turno de entrega de la ayuda.

Es de anotar que lo que aquí se analiza es si la entidad, para motivar su decisión, hizo alusión expresa a la situación fáctica que la víctima planteó en su solicitud, es decir, la situación de vulnerabilidad que le sirve como fundamento para pedir la priorización del turno, por ejemplo, su condición de persona mayor, su estado de discapacidad, el ser madre cabeza de familia, etc., pues sería muy difícil evaluar si la Unidad para las Víctimas realizó una debida ponderación de la situación del caso de la víctima, ya que para esto debería tenerse en cuenta la situación fáctica de las otras miles de solicitudes de priorización.

Tabla 7: Coherencia de las respuestas frente a las ayudas humanitarias

\begin{tabular}{|c|c|c|c|c|}
\hline Tipo de respuestas & Tipo de decisión & Número de casos & Total casos & Porcentaje \\
\hline \multirow{2}{*}{$\begin{array}{l}\text { Teniendo en cuenta la situación fáctica de } \\
\text { la víctima }\end{array}$} & Concediendo & 1 & \multirow{2}{*}{2} & \multirow{2}{*}{$9,5 \%$} \\
\hline & Negando & 1 & & \\
\hline \multirow{2}{*}{$\begin{array}{l}\text { Sin tener en cuenta la situación fáctica de } \\
\text { la víctima }\end{array}$} & Concediendo & 6 & \multirow{2}{*}{10} & \multirow{2}{*}{$47,6 \%$} \\
\hline & Negando & 4 & & \\
\hline \multirow{2}{*}{$\begin{array}{l}\text { Asignando nuevo turno de entrega de la } \\
\text { ayuda pero sin motivación }\end{array}$} & Turno más cercano & 5 & \multirow{2}{*}{9} & \multirow{2}{*}{$42,8 \%$} \\
\hline & Turno más lejano & 4 & & \\
\hline
\end{tabular}

1 Como en el Decreto 4800 de 2011 no se indica de manera expresa un término para responder, se acude al término establecido en la Ley 1437 de 2011 para resolver los derechos de petición. 
1.3.3. Coherencia de las respuestas con las normas jurídicas aplicables

Respecto a la coherencia de las respuestas a las solicitudes de priorización de turno para la entrega de la ayuda humanitaria, se observa que en el primer y segundo tipo de respuestas existe una motivación, es decir, el acto administrativo cita las normas, principios o jurisprudencia sobre la necesidad o no de priorizar el turno de asignación, mientras que en el tercer tipo se asigna un turno como si se tratara de una solicitud normal de entrega de ayuda humanitaria, respuesta que no es coherente con las normas jurídicas aplicables. Así, la incoherencia normativa de las respuestas de la Unidad para las Víctimas es del $42,8 \%$.

\section{Unión Temporal Nuevo Fosyga}

\subsection{Solicitud de indemnización Decreto 3990} de 2007

De los 23 casos estudiados, en 11 de ellos era procedente solicitar la indemnización prevista en el Decreto 3990 de 2007. A continuación se señalan las estadísticas que arrojó la investigación.

\subsubsection{Tiempo de respuesta a la solicitud}

Al respecto es importante señalar que el Decreto 3990 de 2007 no establece de manera expresa un término que permitiera establecer si la respuesta fue oportuna o no, sin embargo, por remisión al procedimiento general fijado tanto en el Decreto 01 de 1984 como en el actual Código de Procedimiento Administrativo y de lo Contencioso Administrativo, se adoptó como tér- mino para resolver 15 días hábiles, asimilando la solicitud a un derecho de petición de interés particular. Así mismo, para efectos de calcular el promedio del tiempo de respuesta se tomó en cuenta la última respuesta de fondo emitida por la entidad, pues es muy frecuente que por cuestiones formales (no se diligenció correctamente el formato FURPEN, no se allegaron documentos originales, etc.) la entidad devuelva la solicitud con todos los documentos y exija a la víctima "subsanar la glosa", es decir, iniciar el trámite de nuevo. Como fue común encontrar que a una misma víctima le fueron devueltos varias veces los documentos no se tuvo en cuenta cada una de las solicitudes presentadas por la víctima y rechazadas por la entidad por aspectos formales, sino el periodo transcurrido entre el momento en que se realizó la primera solicitud y el momento en que recibió una decisión de fondo.

Tabla 8: Tiempo de respuesta solicitudes víctimas de atentados terroristas

\begin{tabular}{|c|c|c|c|}
\hline $\begin{array}{c}\text { Número } \\
\text { de solici- } \\
\text { tudes }\end{array}$ & $\begin{array}{c}\text { Respuestas } \\
\text { oportunas } \\
\text { (15 días) }\end{array}$ & $\begin{array}{c}\text { Respues- } \\
\text { tas extem- } \\
\text { poráneas }\end{array}$ & $\begin{array}{c}\text { Tiempo pro- } \\
\text { medio de } \\
\text { respuesta }\end{array}$ \\
\hline 11 & 0 & 11 & 16 meses \\
\hline $100 \%$ & $0 \%$ & $100 \%$ & \\
\hline
\end{tabular}

2.1.2. Coherencia de las respuestas con las solicitudes

En este punto fue difícil hacer un análisis profundo de la coherencia de las respuestas de la Unión Temporal Nuevo Fosyga con las solicitudes de las víctimas, pues prácticamente todas aparecen rechazadas por cuestiones formales, y en muy raras ocasiones presentan un análisis de fondo del caso. 
2.1.3. Coherencia de las respuestas con las normas jurídicas aplicables

Debido a las pocas respuestas de fondo fue difícil hacer un análisis de la coherencia normativa de las respuestas de la Unión Temporal Nuevo Fosyga, sin embargo, se analizó si estas tuvieron en cuenta la jurisprudencia de la Corte Constitucional sobre la protección a las víctimas de desplazamiento, especialmente en cuanto a los términos administrativos para reclamar el subsidio, pues muchas de las víctimas de minas antipersonales también eran víctimas de desplazamiento, por lo que no habían podido realizar su solicitud dentro del término señalado por el Decreto 3990 de 2007. También se analizó si la entidad tuvo en cuenta la imposibilidad de las víctimas para aportar algunos de los documentos originales exigidos por el mencionado decreto.

Tabla 9: Coherencia respuestas solicitudes víctimas de atentados terroristas

\begin{tabular}{|l|l|c|}
\hline \multicolumn{1}{|c|}{ Motivo negación } & \multicolumn{1}{c|}{ Error } & $\begin{array}{c}\text { Número de } \\
\text { casos }\end{array}$ \\
\hline Solicitud extemporánea & $\begin{array}{l}\text { El funcionario no tuvo en cuenta que el solicitante era también } \\
\text { víctima de desplazamiento forzado, y por esa razón no había } \\
\text { podido realizar su solicitud dentro del término establecido. }\end{array}$ & 1 \\
\hline $\begin{array}{l}\text { No se allegaron todos los documen- } \\
\text { tos originales exigidos por el Decreto } \\
3990 \text { de } 2007\end{array}$ & $\begin{array}{l}\text { El funcionario no aplicó la excepción del artículo } 15 \text { del De- } \\
\text { creto } 1281 \text { de } 2002 \text { sobre imposibilidad de allegar originales, } \\
\text { ni el Decreto } 019 \text { de } 2012 \text { sobre el valor de las copias simples. }\end{array}$ & 6 \\
\hline $\begin{array}{l}\text { No se allegaron todos los documen- } \\
\text { tos exigidos por el Decreto 3990 de } \\
2007\end{array}$ & $\begin{array}{l}\text { El funcionario no tuvo en cuenta la imposibilidad de allegar } \\
\text { algunos documentos (personero y alcalde se niegan a expedir } \\
\text { certificado, junta médica no ha asignado cita para hacer la cali- } \\
\text { ficación de la pérdida de capacidad laboral o no ha entregado } \\
\text { la certificación, la persona es desplazada y no puede retornar } \\
\text { al lugar de los hechos a pedir una certificación del personero, } \\
\text { etc.). }\end{array}$ & 4 \\
\hline
\end{tabular}


2.2. Derechos de petición solicitando información sobre el trámite de reconocimiento y entrega de la indemnización del Decreto 3990 de 2007

2.2.1. Tiempo de respuesta a la solicitud

Tabla 10: Tiempo respuesta derechos de petición ante la UT Nuevo Fosyga

\begin{tabular}{|c|c|c|c|}
\hline $\begin{array}{c}\text { Número de } \\
\text { solicitudes }\end{array}$ & $\begin{array}{c}\text { Respuestas } \\
\text { oportunas } \\
\text { (15 días) }\end{array}$ & $\begin{array}{c}\text { Respuesta } \\
\text { extem- } \\
\text { poráneas }\end{array}$ & $\begin{array}{c}\text { Promedio } \\
\text { tiempo de } \\
\text { respuesta }\end{array}$ \\
\hline 22 & 0 & 22 & 2 meses \\
\hline $100 \%$ & $0 \%$ & $100 \%$ & \\
\hline
\end{tabular}

2.2.2. Coherencia de las respuestas con las solicitudes

En la investigación se detectaron dos clases de respuestas incoherentes a las solicitudes de las víctimas que pedían información sobre el estado de su proceso o la fecha de pago de la indemnización: (i) respuesta solicitando allegar nuevamente todos los documentos porque no se encontraba información sobre el caso (es decir, la entidad había perdido los documentos); (ii) respuesta solicitando algunos documentos que ya habían sido aportados.

Tabla 11: Coherencia respuesta derechos de petición ante la UT Nuevo Fosyga

\begin{tabular}{|l|c|}
\hline \multicolumn{1}{|c|}{ Tipo de respuestas } & Número de casos \\
\hline $\begin{array}{l}\text { Solicitando nuevamente todos los } \\
\text { documentos originales }\end{array}$ & 7 \\
\hline $\begin{array}{l}\text { Solicitando documentos que ya } \\
\text { habían sido radicados }\end{array}$ & 15 \\
\hline
\end{tabular}

2.2.3. Coherencia de las respuestas con las normas jurídicas aplicables

Dado que las respuestas a los derechos de petición solicitando información sobre el estado del proceso se limitaron a pedir de nuevo los documentos no fue posible determinar algún nivel de coherencia con las normas jurídicas aplicables al caso.

\section{B. Procedimientos administrativos: los tortuosos senderos de las víctimas}

La segunda variable del estudio de casos buscó analizar el proceso administrativo en su conjunto, para lo cual se utilizaron los siguientes criterios: (i) facilidad para realizar las declaraciones como víctimas del conflicto y para radicar las demás solicitudes; (ii) información oportuna por parte de los funcionarios sobre el procedimiento administrativo; y (iii) facilidad para la radicación de correspondencia y notificación de los actos administrativos.

\section{Inclusión en el RUV y solicitud de pago de la indemnización administrativa}

En cuanto a la inclusión en el Ruv, se encontró que en términos generales la presentación de la declaración es un procedimiento sencillo y rápido. El problema se presenta cuando la víctima está incluida en el Ruv pero desea hacer otra declaración por un hecho victimizante diferente, pues se detectó que en algunos casos los funcionarios de las personerías se negaron a recibir dicha declaración argumentando que por estar inscrito en el Ruv no era posible hacer- 
lo. Otro problema que se detectó es que en muchas personerías no le entregaban a la víctima la constancia de haber realizado la declaración, complicando el seguimiento posterior del procedimiento. En estos eventos, se presentaron derechos de petición a la Unidad para las Víctimas solicitando información sobre el estado del proceso, informando el lugar y fecha de la declaración, sin embargo en algunos casos fue necesario volver a hacer la declaración e iniciar nuevamente el procedimiento pues las declaraciones nunca aparecieron.

Finalmente, en lo relativo a la radicación de correspondencia y notificación de los actos administrativos se identificaron dos problemas: (i) las víctimas deben acudir al centro de correspondencia de la Unidad para las Víctimas ubicado en Fontibón, pues en las demás sedes de la ciudad generalmente no les reciben sus solicitudes, y aunque pueden escanear los documentos y radicarlos vía correo electrónico en la práctica la respuesta es más rápida si radican los documentos en medio físico; y (ii) generalmente, las resoluciones de inclusión o no inclusión en el Ruv no son debidamente notificadas. Simplemente le envían un oficio a la víctima indicándole la decisión.

\section{Ayudas humanitarias}

Las solicitudes de ayuda humanitaria y de prioridad en el turno de entrega de esta no requieren mayor formalidad. Los formatos que deben diligenciar generalmente son entregados en los superCADE pero la orientación que se le brinda a las víctimas no es precisamente la mejor, pues algunos funcionarios no tienen claridad sobre las diferentes clases de ayuda humanitaria y no es raro que entreguen a las víctimas de hechos victimizantes diferentes al desplazamiento forzado el formato de solicitud de ayuda humanitaria para víctimas del desplazamiento, ocasionando la negativa de la solicitud por parte de la Unidad para las Víctimas. Adicionalmente, en la línea telefónica de atención e información a las víctimas solo pueden consultar el turno de entrega pero no les brindan información sobre la fecha probable de entrega de la ayuda.

Finalmente, en lo relativo a la radicación de correspondencia y notificación de los actos administrativos, a diferencia de lo señalado sobre el trámite de la indemnización administrativa, el hecho de que puedan radicar las solicitudes de ayuda humanitaria en los superCADE les facilita mucho este trámite. No obstante, la notificación de los actos que reconocen la ayuda presentan dos problemas: (i) los oficios concediendo la ayuda e informando que deben reclamarla en el Banco Agrario no son enviados oportunamente a las víctimas; (ii) debido a lo anterior y a que el dinero de las ayudas humanitarias permanece en el banco por un periodo determinado, si las víctimas pierden el turno de entrega no solo es posible que cuando se presenten a reclamarla ya el dinero haya sido devuelto a la Unidad para las Víctimas, sino que deben iniciar un nuevo procedimiento administrativo para solicitar el retorno de dichos dineros. 
3. Solicitud de indemnización Decreto 3990 de 2007

En este caso los problemas son varios. En primer lugar, en Bogotá solo existe un punto de radicación de solicitudes y correspondencia. En segundo lugar, el Formulario único de reclamación de indemnizaciones por accidentes de tránsito, eventos catastróficos, terroristas y catástrofes naturales (FURPEN) debe acompañarse de los certificados originales de pérdida de la capacidad laboral y de constatación de los hechos, el primero expedido por la Junta Regional de Certificación y el segundo por el personero o alcalde del respectivo lugar. El procedimiento para la víctima inicia con la solicitud de la certificación de los hechos en la personería o la alcaldía del lugar; posteriormente debe consignar en una corporación bancaria el costo de la valoración médica (un salario mínimo legal diario) que le permitirá, una vez asignada la cita, obtener de la Junta Regional de Certificación de pérdida de la capacidad laboral la certificación mencionada (el promedio de espera es de seis meses aproximadamente); finalmente, debe acudir a la Unión Temporal Nuevo Fosyga a radicar todos los documentos. ${ }^{2}$ En tercer lugar, no existe un canal especial para brindar información a las víctimas de atentados terroristas, por ejemplo, en la página web de la entidad (www. utnuevofosyga.com) no hay información sobre el procedimiento, de hecho, ni siquiera aparecen los números telefónicos de la entidad.

2 El análisis respecto a los obstáculos frente a las reclamaciones ante la Unión Temporal Nuevo Fosyga se limitó a la ciudad de Bogotá, en razón a que el estudio solo cubre los casos asesorados por el Consultorio Jurídico de la Universidad de los Andes.
Por último, las solicitudes deben radicarse personalmente, pues si se envían por correo no es posible obtener el número de radicado del proceso, necesario para posteriormente solicitar información sobre el trámite.

\section{La acción de tutela: la esperanza de las víctimas}

La tercera variable de la investigación se centró en el análisis del proceso de tutela, alternativa judicial a la cual acuden normalmente las víctimas ante las largas esperas o las respuestas contradictorias de las entidades administrativas encargadas de proteger sus derechos. Para este análisis se usaron tres criterios: (i) protección formal del derecho; (ii) cumplimiento de la administración a los fallos de tutela y a los requerimientos de los jueces; y (iii) diligencia del juzgado para adelantar el incidente de desacato.

\section{Protección formal del derecho}

Respecto a este primer criterio se analizaron: (i) las causas frecuentes por las que debieron acudir a la acción de tutela; (ii) las tutelas concedidas y negadas, así como los argumentos de los jueces de tutela para negarlas; y (iii) la coherencia entre los derechos que se solicitaba fueran protegidos en la acción de tutela y los derechos finalmente amparados por la sentencia judicial. 


\subsection{Hechos que motivaron la interposición de las acciones de tutela}

Tabla 12: Hechos por los que las víctimas acuden a la tutela

\begin{tabular}{|c|c|c|}
\hline Hecho que motivó la tutela & Entidad responsable & Número de casos \\
\hline $\begin{array}{l}\text { No respuesta al derecho petición solicitando información sobre la ins- } \\
\text { cripción en el RUV }\end{array}$ & \multirow{9}{*}{ Unidad para las Víctimas } & 5 \\
\hline No respuesta a la solicitud de inscripción en el RUV & & 4 \\
\hline No respuesta a los recursos contra acto que niega inscripción en el RUV & & 4 \\
\hline Negativa a inscripción en el RUV & & 2 \\
\hline $\begin{array}{l}\text { No respuesta al derecho de petición solicitando información sobre el } \\
\text { pago de indemnización administrativa }\end{array}$ & & 2 \\
\hline No respuesta a solicitud de ayuda humanitaria & & 7 \\
\hline $\begin{array}{l}\text { No respuesta a solicitud de prioridad en el turno de entrega de la ayuda } \\
\text { humanitaria }\end{array}$ & & 4 \\
\hline Negativa de prioridad en el turno de entrega de la ayuda humanitaria & & 2 \\
\hline No cumplimiento del fallo de tutela & & 1 \\
\hline $\begin{array}{l}\text { No respuesta al derecho petición pidiendo información sobre trámite de } \\
\text { la solicitud de indemnización D. } 3990 \text { de } 2007\end{array}$ & \multirow{2}{*}{$\begin{array}{l}\text { Unión Temporal Nuevo } \\
\text { Fosyga }\end{array}$} & 4 \\
\hline Negativa de pago de la indemnización D. 3990 de 2007 & & 1 \\
\hline
\end{tabular}

\subsection{Fallos de tutela}

Todas las tutelas interpuestas en materia de reparación administrativa fueron concedidas en primera instancia, y de las relativas a ayudas humanitarias solo dos fueron negadas en primera instancia: una porque el juez consideró que la entidad sí había respondido la petición pero no tuvo en cuenta que no era coherente con la solicitud; la otra, referida a la priorización del turno de entrega de la ayuda, porque el a Tabla 13: Efectividad formal de la acción de tutela

\begin{tabular}{|l|c|c|c|}
\hline \multicolumn{1}{|c|}{ Tema } & $\begin{array}{c}\text { Tutelas in- } \\
\text { terpuestas }\end{array}$ & $\begin{array}{c}\text { Tutelas } \\
\text { concedidas }\end{array}$ & $\begin{array}{c}\text { Tutelas } \\
\text { negadas }\end{array}$ \\
\hline $\begin{array}{l}\text { Reparación ad- } \\
\text { ministrativa }\end{array}$ & 18 & 18 & 0 \\
\hline $\begin{array}{l}\text { Ayudas humani- } \\
\text { tarias }\end{array}$ & 13 & 11 & 2 \\
\hline $\begin{array}{l}\text { Indemnización } \\
\text { Fosyga }\end{array}$ & 5 & 4 & 1 \\
\hline
\end{tabular}
quo estimó que no era procedente puesto que atentaba contra el derecho a la igualdad de los demás desplazados, sin considerar la especial situación de vulnerabilidad del usuario.

\subsection{Coherencia de las sentencias}

Aunque en la mayoría de los casos se solicitaba proteger el derecho de petición, en otros, además de este se alegaba vulneración del debido 
proceso administrativo ante las recurrentes respuestas incoherentes o contradictorias de la entidad, o del derecho de igualdad en las relativas a la prioridad en el turno de entrega de las ayudas humanitarias, por ejemplo. En un caso concreto se invocó, con fundamento en la jurisprudencia de la Corte Constitucional, la protección al derecho de la víctima a la verdad, la justicia y la reparación, por cuanto a pesar de que existía un fallo de tutela ordenando una respuesta de fondo sobre su reparación administrativa, la Unidad para las Víctimas no lo acataba y el juez tampoco imponía las sanciones del Decreto 2591 ni utilizaba los medios necesarios para lograr el cumplimiento de su sentencia. Además, generalmente los jueces tutelaban el derecho de petición pero no se pronunciaban frente a los demás derechos fundamentales.

Tabla 14: Coherencia entre derecho vulnerado y derecho tutelado

\begin{tabular}{|l|c|}
\hline \multicolumn{1}{|c|}{ Derecho invocado } & $\begin{array}{c}\text { Derecho tutelado en } \\
\text { la sentencia }\end{array}$ \\
\hline Derecho de petición & $100 \%$ de los casos \\
\hline Debido proceso administrativo & $10 \%$ de los casos \\
\hline Derecho a la igualdad & $50 \%$ de los casos \\
\hline $\begin{array}{l}\text { Derecho de las víctimas a la } \\
\text { verdad, justicia y reparación }\end{array}$ & $0 \%$ de los casos \\
\hline
\end{tabular}

\section{Cumplimiento de la administración a los fallos de tutela y a los requerimientos de los jueces}

Aquí se buscó establecer el nivel de observancia de la Unidad para las Víctimas y la Unión Temporal Nuevo Fosyga a tres tipos de requerimientos judiciales que se pueden producir dentro del trámite de la acción de tutela y su incidente de desacato: (i) respuesta al informe previsto en el artículo 19 del Decreto 2591 de 1991; (ii) cumplimiento del fallo de tutela; y (iii) cumplimiento a los requerimientos dentro del trámite del incidente de desacato.

\subsection{Respuesta al informe del art. 19 del Decreto 2591 de 1991}

Tabla 15: Respuesta a las pretensiones de las tutelas

\begin{tabular}{|l|c|c|c|c|}
\hline \multirow{2}{*}{ Entidad } & \multicolumn{2}{|c|}{ Responde } & \multicolumn{2}{c|}{ No responde } \\
\cline { 2 - 5 } & $\begin{array}{c}\text { No. de } \\
\text { casos }\end{array}$ & Porcentaje & $\begin{array}{l}\text { No. de } \\
\text { casos }\end{array}$ & Porcentaje \\
\hline $\begin{array}{l}\text { Unidad } \\
\text { para las } \\
\text { Víctimas }\end{array}$ & 21 & $67 \%$ & 10 & $33 \%$ \\
\hline $\begin{array}{l}\text { Unión } \\
\text { Temporal } \\
\text { Nuevo } \\
\text { Fosyga }\end{array}$ & 4 & $80 \%$ & 1 & $20 \%$ \\
\hline
\end{tabular}

\subsection{Cumplimiento del fallo dentro del plazo fijado por la sentencia}

Se tuvieron en cuenta: los casos que se cumplieron oportunamente, aquellos en los que se cumplió la orden del juez extemporáneamente y los que frente a un incumplimiento prolongado fue necesario iniciar un incidente de desacato. 
Tabla 16: Acatamiento de los fallos de tutela

\begin{tabular}{|l|c|c|c|c|c|c|}
\hline \multirow{2}{*}{ Entidad } & \multicolumn{2}{|c|}{ Cumplimiento oportuno } & \multicolumn{2}{c|}{$\begin{array}{c}\text { Cumplimiento extem- } \\
\text { poráneo }\end{array}$} & \multicolumn{2}{c|}{ Incumplimiento } \\
\cline { 2 - 7 } & $\begin{array}{c}\text { No. de } \\
\text { casos }\end{array}$ & Porcentaje & $\begin{array}{c}\text { No. de } \\
\text { casos }\end{array}$ & Porcentaje & $\begin{array}{c}\text { No. de } \\
\text { casos }\end{array}$ & Porcentaje \\
\hline Unidad para las Víctimas & 2 & $6,4 \%$ & 10 & $32,2 \%$ & 19 & $61,2 \%$ \\
\hline $\begin{array}{l}\text { Unión Temporal Nuevo } \\
\text { Fosyga }\end{array}$ & 1 & $20 \%$ & 2 & $40 \%$ & 2 & $40 \%$ \\
\hline
\end{tabular}

2.3. Cumplimiento a los requerimientos dentro del trámite del incidente de desacato

Las respuestas de las entidades a los requerimientos del juez dentro del trámite del incidente de desacato se clasificaron en tres grupos: (i) respuestas oportunas y de fondo al requerimiento del juez; (ii) respuestas extemporáneas pero coherentes con el requerimiento del juez; y (iii) ausencia de respuesta de la entidad al requerimiento del juez, o respuestas incoherentes tendientes a dilatar el proceso. Dentro de este último grupo están los casos en los que el juez hace varios requerimientos a la entidad y esta guarda silencio, responde algo diferente a lo exigido o solicita documentos que generalmente ya fueron aportados por las víctimas.

Tabla 17: Acatamiento a las órdenes del juez dentro del incidente de desacato

\begin{tabular}{|l|c|c|c|c|c|c|}
\hline \multirow{2}{*}{ Entidad } & \multicolumn{2}{|c|}{ Cumplimiento oportuno } & \multicolumn{2}{c|}{ Cumplimiento extemporáneo } & \multicolumn{2}{c|}{ Incumplimiento } \\
\cline { 2 - 6 } & No. de casos & Porcentaje & No. de casos & Porcentaje & No. de casos & Porcentaje \\
\hline $\begin{array}{l}\text { Unidad para las } \\
\text { Víctimas }\end{array}$ & 3 & $15,85 \%$ & 4 & $21,05 \%$ & 12 & $63,1 \%$ \\
\hline $\begin{array}{l}\text { Unión Temporal } \\
\text { Nuevo Fosyga }\end{array}$ & 0 & $0 \%$ & 1 & $50 \%$ & 1 & $50 \%$ \\
\hline
\end{tabular}

3. Diligencia del juzgado para adelantar el incidente de desacato tendiente al cumplimiento del fallo judicial

Las anteriores estadísticas evidencian el incumplimiento generalizado de las entidades, especialmente de la Unidad para las Víctimas, a los requerimientos del juez dentro del incidente de desacato. Ahora lo que se analiza es la actitud del juez frente a estos incumplimientos, con base en los siguientes criterios: (i) término que tarda el juez para expedir el auto de apertura del incidente y hacer el primer requerimiento a la entidad; (ii) actitud del juez frente al incumplimiento de la entidad a su requerimiento; (iii) término promedio de duración de un incidente de desacato. 


\subsection{Apertura del incidente de desacato}

Tabla 18: Tiempo que demora el juez en emitir auto de apertura del incidente

\begin{tabular}{|l|c|c|}
\hline $\begin{array}{l}\text { Promedio de tiempo para } \\
\text { que el juez dé apertura al } \\
\text { incidente de desacato }\end{array}$ & $\begin{array}{c}\text { No. de } \\
\text { casos }\end{array}$ & Porcentaje \\
\hline Entre una semana y un mes & 15 & $71,4 \%$ \\
\hline Entre un mes y dos meses & 5 & $23,8 \%$ \\
\hline Más de tres meses & 1 & $4,8 \%$ \\
\hline
\end{tabular}

\subsection{Actitud del juez frente al incumplimiento de la entidad a su requerimiento}

Tabla 19: Actuaciones del juez ante el incumplimiento de sus órdenes

\begin{tabular}{|l|c|c|}
\hline $\begin{array}{l}\text { Actuaciones del juez frente al } \\
\text { incumplimiento }\end{array}$ & $\begin{array}{c}\text { No. de } \\
\text { casos }\end{array}$ & Porcentaje \\
\hline $\begin{array}{l}\text { Envía nuevo requerimiento en } \\
\text { similares términos al inicial }\end{array}$ & 8 & $30,1 \%$ \\
\hline $\begin{array}{l}\text { Envía nuevo requerimiento in- } \\
\text { dicando que si no responde se } \\
\text { pueden aplicar sanciones }\end{array}$ & 13 & $61,9 \%$ \\
\hline $\begin{array}{l}\text { Aplica sanciones del Decreto } \\
2591 \text { y oficia al superior para } \\
\text { que cumpla la sentencia }\end{array}$ & 0 & $0 \%$ \\
\hline
\end{tabular}

\subsection{Duración de un incidente de desacato}

En este criterio se analiza el tiempo que lleva lograr que se cumpla la sentencia del juez. Para esto se promedió el tiempo que transcurre entre el inicio de la apertura del incidente de desacato y el momento en que finalmente la entidad cumple el fallo judicial. Es de señalar que algunos casos clasificados en la categoría de 4 a 12 meses aún están pendientes de cumplimiento, y en la categoría de más de 12 meses fue ne- cesario interponer dos acciones de tutela: una contra la inoperancia del juez, la cual fue fallada a favor y después de casi dos años se logró el cumplimento del fallo judicial; otra contra el juez por la denegación de justicia, y está pendiente de la decisión del juez de tutela.

Tabla 19: Tiempo que toma el cumplimiento de un fallo de tutela

\begin{tabular}{|l|c|c|}
\hline $\begin{array}{l}\text { Promedio de duración de un } \\
\text { incidente de desacato }\end{array}$ & $\begin{array}{c}\text { No. de } \\
\text { casos }\end{array}$ & Porcentaje \\
\hline Entre uno y tres meses & 4 & $19 \%$ \\
\hline Entre cuatro y doce meses & 15 & $71,4 \%$ \\
\hline Más de doce meses & 2 & $9,6 \%$ \\
\hline
\end{tabular}

\section{LA REPARACIÓN: DE LA TEORÍA A LA REALIDAD}

En la primera parte de este escrito se realizó un análisis formal de las normas sobre la reparación, las ayudas humanitarias y la indemnización a las víctimas de eventos terroristas. La conclusión general fue que dichas normas, salvo el caso del Decreto 3990 de 2007, establecen procedimientos sencillos, rápidos y con varias garantías para las víctimas. En la segunda parte se hizo un análisis material, es decir, se miró cómo operan estos procedimientos en la realidad, para lo cual se estudiaron las respuestas de las entidades a las víctimas (actos administrativos); los trámites que deben adelantar las víctimas (procedimientos administrativos); y (iii) la eficacia, medida en tiempo y coherencia, de las sentencias de los jueces constitucionales (los procesos de tutela). Ahora, corresponde contrastar las normas y sus procesos, formal- 
mente garantistas, con los procedimientos, ya no tan garantistas, que en la práctica deben adelantar las víctimas.

\section{A. Reparación administrativa}

Del análisis formal se concluyó que el procedimiento que deben seguir las víctimas para conseguir la reparación por vía administrativa es claro, rápido e informal. Sin embargo, el estudio de casos mostró que no es tan claro para todos, ni tan rápido e informal. En primer lugar, porque en la práctica el tiempo que deben esperar las víctimas para recibir una respuesta a su solicitud de inclusión en el Ruv es de cinco meses en promedio, es decir, casi el doble del establecido en la norma (sesenta días hábiles). En cuanto a los derechos de petición el panorama es más desalentador: en promedio la Unidad para las Víctimas tarda nueve meses para responderlos, aunque se observó que a mediados del primer semestre de 2013 este tiempo empezó a disminuir. Sin embargo, se siguen presentando problemas con la coherencia de las respuestas.

En segundo lugar, aunque formalmente las normas sobre la declaración ante el Ministerio Público son claras, en la práctica algunos funcionarios no las aplican bien, por ejemplo, cuando las víctimas se presentan a declarar nuevos hechos victimizantes no falta quienes se niegan a recibirlas, argumentando que una misma persona no puede realizar dos declaraciones. Aunado a lo anterior, algunos personeros, especialmente en el primer y segundo semestre de 2012, no entregaron a la víctima la constancia de haber realizado su declaración, lo cual dificulta el seguimiento del caso.
En cuanto a la informalidad, esta no es tan cierta si te tiene en cuenta que se sigue exigiendo una carga probatoria excesiva a las víctimas, por ejemplo, en el 50\% de los actos que negaron la inclusión en el Ruv se argumentó que no estaba probada la condición de víctima o que los hechos tuvieran relación con el conflicto armado, es decir, el funcionario no aplicó las funciones oficiosas para decretar las pruebas que consideraba necesarias, y tomó su decisión únicamente con base en los documentos que la víctima aportó. El otro $50 \%$ de los casos negados obedecieron a interpretaciones equivocadas de las normas aplicables. Finalmente, de los 23 casos estudiados, solo en 9 de ellos se ha entregado la indemnización administrativa, otros 7 están a la espera de la inclusión en el Ruv o de la respuesta a los recursos contra el acto que la negó, y 7 están a la espera de que el Estado, en aplicación de los principios de progresividad y gradualidad, entregue la indemnización económica a las víctimas.

\section{B. Ayuda humanitaria}

Al igual que en la reparación, las normas sobre las ayudas humanitarias son relativamente claras y el procedimiento sencillo. El estudio de casos, sin embargo, concluyó que: (i) el tiempo promedio de respuesta a una solicitud de ayuda humanitaria o de prioridad en el turno de entrega de la ayuda es de tres meses; (ii) en la mayoría de los casos fue necesario acudir a la acción de tutela para recibir una respuesta; y (iii) los actos administrativos no tienen una adecuada motivación y, generalmente, la respuesta se basa en un formato que no tiene en cuenta la situación 
fáctica del solicitante, especialmente en el caso de las solicitudes de priorización de turnos, por consiguiente, el 90,4\% de las respuestas estudiadas no hacen alusión a los argumentos esgrimidos en la solicitud. Estas falencias hacen que en la práctica se desconozca la finalidad de estas ayudas y su carácter fundamental (sentencias T-025 de 2004, T-868 de 2008, T-462 de 2012, entre otras), especialmente en el caso de las personas en condición de discapacidad, las cuales tienen derecho a la prórroga automática de la ayuda (sentencia T-856 de 2011), disposición que muy pocas veces opera. Así, aunque en teoría las víctimas tienen derecho a recibir una ayuda por tres meses, y después de ese término pedir la prórroga, la realidad es que les debe durar para un año debido a las demoras en la respuesta a la solicitud de prórroga, el tiempo de espera en el turno de entrega, y en algunos casos el tiempo que demora el trámite de la acción de tutela y su incidente de desacato.

\section{Indemnización del Decreto 3990 de 2007}

Del análisis formal del Decreto 3990 de 2007 se concluyó que la norma no es clara, debido a su lenguaje técnico, al alto grado de formalismo (se exigen varios documentos en original) y a que no hay un límite de tiempo expreso para la respuesta por parte de la entidad. Por otro lado, el análisis material tampoco fue muy alentador: el tiempo promedio de respuesta es de 16 meses, es decir, la víctima debe esperar aproximadamente año y medio para recibir una respuesta de fondo, además, es muy frecuente que por cuestiones formales la entidad le devuelva la solicitud con todos los documentos y le exija iniciar el trámite de nuevo.

Contrariamente, a las víctimas sí les exige radicar la solicitud dentro de un año contado a partir del hecho, término que es cumplido estrictamente por la Unión Temporal Nuevo Fosyga sin tener en cuenta situaciones excepcionales, como la condición de desplazado; las dificultades propias de su lesión pues la mayoría de los solicitantes son víctimas de minas antipersonales; la imposibilidad para allegar todos los documentos en el término estipulado por el Decreto 3990 de 2007 ya que algunos dependen de la buena voluntad de funcionarios públicos, como ocurre con las certificaciones que deben expedir los personeros y las Juntas de Calificación de la Pérdida de Capacidad Laboral. Por último, muchas víctimas pierden la oportunidad de obtener esta indemnización por desconocimiento de la norma.

\section{La acción de tutela}

Si bien existe una protección formal de los derechos de las víctimas, esta contrasta con la desprotección material que las víctimas viven en la práctica debido a la indiferencia de las entidades a los fallos de tutela, y a la lentitud de los jueces para hacer cumplir sus fallos judiciales. En efecto, aunque el 91\% de las tutelas interpuestas fueron falladas a favor de las víctimas, solo el $9 \%$ de estos fallos favorables fueron acatados por la entidad accionada dentro del término señalado por el juez. En los demás casos las entidades cumplieron extemporáneamente el fallo de tutela, por lo que en total, de todas 
las tutelas interpuestas y falladas a favor, en el $58 \%$ de los casos fue necesario iniciar un incidente de desacato para lograr el cumplimiento del fallo judicial. Así las cosas, el incidente de desacato pasó de ser una etapa contingente a una etapa habitual dentro del proceso de tutela.

Ahora bien, a diferencia del trámite de la tutela, el Decreto 2591 de 1991 no establece términos para que el juez resuelva sobre el incumplimiento del accionante a lo ordenado dentro del incidente de desacato, por lo tanto, la víctima debe esperar un mes en promedio para que el juez ordene la apertura del incidente de desacato y requiera a la entidad accionada para que cumpla el fallo o informe por qué no lo ha cumplido, requerimiento que en el $62 \%$ de los casos es ignorado por la entidad accionada, obligando a la víctima a esperar pacientemente a que el expediente entre al despacho, y al cabo de varias semanas o meses el juez envíe un nuevo requerimiento. En otros casos, la entidad responde con argumentos incoherentes que solo buscan dilatar el trámite del incidente, originando un ir y venir de oficios entre el juez, la Unidad para las Víctimas -memoriales solicitando nuevos documentos, informando que el caso se encuentra en estudio o afirmando que ya cumplió el falloy la víctima -memoriales informando que la Unidad para las Víctimas no ha cumplido el fallo y suplicando al juez que aplique las sanciones previstas en el Decreto 2591 de 1991-.

En conclusión, los procedimientos administrativos que las víctimas tienen que adelantar ante la Unidad para las Víctimas y la Unión Temporal Nuevo Fosyga son un obstáculo para lograr la re- paración administrativa, por lo que las víctimas generalmente tienen que acudir a la acción de tutela para buscar la satisfacción de sus derechos por vía judicial. Sin embargo, a diferencia de lo que se intuía en la hipótesis inicial, las causas de la ineficacia de estos procedimientos administrativos no son únicamente la demora en las respuestas a las solicitudes de indemnización administrativa y la falta de recursos económicos para entregar las indemnizaciones pecuniarias, sino también las respuestas incoherentes y contradictorias de la Unidad para las Víctimas y la Unión Temporal Nuevo Fosyga, y las cargas desproporcionadas exigidas a las víctimas para demostrar la ocurrencia de los hechos victimizantes. Igualmente, contrario a lo pensado al inicio de la investigación, la acción de tutela es por lo general poco eficiente en cuanto a proteger los derechos de las víctimas, por tres razones: (i) la indiferencia de la Unidad para las Víctimas y la Unión Temporal Nuevo Fosyga hacia los fallos judiciales; (ii) las demoras excesivas de los jueces para tramitar el incidente de desacato; y (iii) la ausencia de sanciones por el incumplimiento de los fallos de tutela.

\section{EL TIEMPO DE LAS REPARACIONES: PROBLEMAS Y POSIBLES SOLUCIONES}

La investigación presentada anteriormente evidenció varias falencias dentro de los procedimientos administrativos a los que se enfrentan las víctimas del conflicto armado en busca de la indemnización administrativa o la entrega de ayudas humanitarias, carencias que muestran un panorama poco alentador para las víctimas 
y unas entidades poco comprometidas con el derecho a la reparación de estas. Sin embargo, antes de entrar a analizar los resultados de esta investigación es necesario indicar las ventajas y limitaciones de la metodología usada, para finalmente proponer algunas soluciones a los problemas que se identificaron en el proceso investigativo.

\section{A. Ventajas y limitaciones del estudio de casos}

Como se puede observar, la metodología usada se centró en el estudio de 23 casos adelantados por el Área de Derecho Público del Consultorio Jurídico de la Universidad de los Andes. Así las cosas, la muestra es bastante reducida si se tienen en cuenta las 6.657.985 víctimas registradas víctimas registradas en el Ruv al 13 de agosto de 2014, según la página web de la Unidad para las Víctimas. Por ende, las conclusiones de la investigación deben ser vistas con cautela, y sus resultados, susceptibles de error, pueden no coincidir totalmente con el contexto general en el que el Estado desarrolla su política de reparación. No obstante, aunque reducida, la muestra puede ser un buen indicador de lo que están viviendo las demás víctimas que están buscando su reparación, especialmente si se tiene en cuenta que en estos 23 casos, a pesar de que las víctimas han estado acompañadas por estudiantes del Consultorio Jurídico, quienes con la orientación de los docentes del Consultorio les brindan la asesoría jurídica tendiente al reconocimiento de su calidad de víctimas y consecuente reparación, los procedimientos administrativos han sido largos e intrincados, por lo que probablemente la situación de quienes no cuentan con este apoyo jurídico no sea mejor.

Por otro lado, la investigación no tuvo en cuenta los trabajos realizados por otros académicos sobre el tema de la reparación, lo cual podría ser visto como una grave deficiencia metodológica, sin embargo, de hecho, es una consecuencia lógica del planteamiento del problema de investigación, pues a través del uso de variables, cada una de ellas con criterios claros y definidos, se hizo primero un estudio formal de los procedimientos administrativos, para después comparar los resultados con el estudio material de unos casos determinados, con la finalidad de contrastar las formas jurídicas con la realidad de los casos en estudio. De ese modo, la metodología es coherente con el objetivo de la investigación: determinar si los trámites administrativos que deben adelantar las víctimas que acuden al Consultorio Jurídico de la Universidad de los Andes son idóneos y efectivos para lograr la reparación establecida en la Ley 1448 de 2011, así como la entrega de las ayudas humanitarias y la indemnización del Decreto 3990 de 2007. En otras palabras, la investigación no buscaba describir el panorama general de la reparación de las víctimas en Colombia, sino indagar, a través de un estudio de casos, los posibles problemas de las políticas de reparación administrativa y asistencia a las víctimas.

\section{B. Principales problemas y sus posibles causas}

Frente a la Unidad para las Víctimas, la investigación identificó los siguientes problemas: (i) 
demoras excesivas en las respuestas; (ii) respuestas contradictorias e incoherentes; e (iii) incumplimiento de las órdenes judiciales. Una posible causa tanto de la demora como de la mala calidad de sus respuestas, seguramente es la gran cantidad de solicitudes como consecuencia de las constantes violaciones de derechos humanos en el país, pero también de las personas que se hacen pasar por víctimas para obtener beneficios económicos, lo cual afecta la capacidad operativa de la entidad.

Ahora, respecto al incumplimiento de las órdenes judiciales las consecuencias son graves, puesto que se atenta contra el estado de derecho toda vez que si el Gobierno, representado por la Unidad para las Víctimas, no acata las órdenes de los jueces de la República da un mal ejemplo a las demás entidades públicas y privadas, y la justicia no solo pierde eficacia sino también credibilidad ante los ciudadanos.

En cuanto a la Unión Temporal Nuevo Fosyga, además de los problemas de publicidad y claridad de las normas, las víctimas deben enfrentarse a una entidad cuyos funcionarios no están capacitados para tratar con víctimas de la violencia, por lo que muchas veces terminan revictimizando a los solicitantes de la indemnización con trámites engorrosos, exigencias desmedidas frente a los documentos que deben presentar, y la demora excesiva en decidir de fondo las solicitudes. Pareciera que ni el Decreto 019 de 2012 ni los principios de la Ley 1437 de 2011 que buscan "desformalizar" los procedimientos administrativos no aplicarán para esta entidad. Dos ejemplos de esto son la exigencia de docu- mentos originales y la devolución de las solicitudes cuando falta un documento.

Un caso que ilustra claramente la inoperancia de esta entidad es el de una víctima de una mina antipersonal, que a pesar de las severas lesiones por la explosión se vio obligada a desplazarse de su lugar de residencia, lo que le impidió presentar la solicitud con todos los documentos dentro del año siguiente a los hechos. No obstante lo anterior, decidió radicar los documentos argumentando su condición de desplazamiento, y solicitando la suspensión del término de caducidad, tal y como lo ordena la jurisprudencia de la Corte Constitucional. Sin embargo, la entidad negó la solicitud por extemporánea sin siquiera referirse a los argumentos presentados por la víctima; igualmente, los jueces negaron la tutela en ambas instancias, por lo que el equipo del Consultorio Jurídico acudió a la Corte Constitucional, quien seleccionó el caso para revisión. Ahora, la víctima está a la espera de la sentencia de la Corte Constitucional.

Finalmente, de los resultados de la investigación se puede concluir que aunque formalmente la acción de tutela es efectiva para proteger los derechos fundamentales, la indiferencia de la Unidad para las Víctimas para acatar los fallos y la parsimonia de los jueces para hacerlos cumplir e imponer las sanciones pertinentes hacen de esta acción constitucional un instrumento poco eficiente. Llama la atención el contraste entre la rapidez de los jueces para emitir la sentencia de tutela y su lentitud para adelantar los incidentes de desacato, los cuales están pasando de la excepción a la regla. Como lo muestra clara- 
mente la investigación, en el $58 \%$ de las tutelas fue necesario interponer el incidente de desacato, $y$ de los 21 incidentes adelantados ninguno ha recibido una sola sanción, a pesar de que el $62 \%$ de los requerimientos de los jueces fueron olímpicamente ignorados.

\section{Posibles soluciones}

\section{Frente a la Unidad para las Víctimas}

Una solución obvia, y un tanto simplista, sería incrementar el presupuesto de la entidad para que pueda contratar más funcionarios $\mathrm{y}$, de esa forma, (i) responder las solicitudes no solo dentro de los términos legales sino de manera oportuna y coherente con lo que las víctimas solicitan; y (ii) pagar las indemnizaciones y entregar las ayudas humanitarias en un término razonable, evitando así el largo calvario que deben padecer las víctimas. No obstante, el problema no es solo la falta de presupuesto para contratar más personal o pagar las indemnizaciones económicas; mientras el conflicto armado no cese seguirán aumentando las víctimas reales y más personas estarán haciéndose pasar por víctimas, lo primero es consecuencia de pretender reparar durante el conflicto y no al final de este, y lo segundo, debido a la cultura tramposa y a la falta de sanciones para los suplantadores de víctimas.

Muchas de las respuestas contradictorias e incoherentes ofrecidas por la Unidad para las Víctimas tanto a las víctimas como a los jueces de tutela se deben no siempre a la falta de tiempo para analizar los casos sino a problemas admi- nistrativos. Específicamente, se pueden mencionar tres. Uno, la falta de un registro unificado de solicitudes que evite, por un lado, que por una misma solicitud se emitan dos respuestas y, por otro, que las personas soliciten simultáneamente ayuda en diferentes ciudades. Dos, el uso excesivo de formatos de respuesta. Si bien Ios formatos ayudan al funcionario a responder con mayor prontitud, le impiden hacerlo de manera fundamentada y adecuada al caso concreto. Debería haber cierta flexibilidad, por ejemplo, establecer una plantilla base pero admitir que el funcionario pueda exponer las razones pertinentes al caso concreto. Tres, la falta de unificación de criterios. En los casos analizados se evidenciaron respuestas disímiles a hechos victimizantes similares. Por ejemplo, un funcionario negó la inclusión en el Ruv a una víctima porque consideró que la lesión causada por una mina antipersonal no se enmarcaba dentro del conflicto armado, cuando es bien sabido que los únicos que las colocan son los grupos armados ilegales, no la delincuencia común; el otro caso en que se negó la inclusión en el Ruv está relacionado con el reclutamiento forzado de menores. Situaciones como estas podrían reducirse si la entidad emite circulares o conceptos sobre la interpretación y aplicación de ciertas normas jurídicas, al tiempo que brinda una adecuada capacitación a sus funcionarios.

\section{Frente a la Unión Temporal Nuevo} Fosyga

Además de la divulgación del Decreto 3990 de 2007 es necesario "desformalizar" este procedimiento y enfocarlo en la atención a víctimas 
del conflicto armado, pues la Unión Temporal actualmente está desconociendo la tendencia del moderno derecho administrativo a eliminar trámites innecesarios, reducir la formalidad y brindar una mejor atención a los ciudadanos. Por ejemplo, en lugar de devolver a la víctima la solicitud junto con todos los documentos debería informarle lo que le falta, permitirle presentar copias simples (fotocopia) de algunos documentos y darle un tiempo razonable para hacerlo, teniendo en cuenta que muchos de los solicitantes son personas en condición de desplazamiento y algunos de los certificados los deben tramitar justamente en los sitios que tuvieron que abandonar para salvaguardar sus vidas.

\section{Procesos de tutela}

Frente al reiterado incumplimiento por parte de la Unidad para las Víctimas de los requerimientos del juez, es indispensable que estos apliquen las sanciones previstas en los artículos 27, 52 y 53 del Decreto 2591 de 1991, pues su competencia no termina con la protección formal del derecho, es decir, con la expedición de la sentencia, sino con el cumplimiento efectivo de su fallo, en otras palabras, el juez de tutela debe garantizar la protección material del derecho.

Por otra parte, es necesario establecer una reglamentación clara sobre los términos del trámite del incidente de desacato para evitar que unos juzgados se remitan al Código de Procedimiento Civil (en aplicación de lo dispuesto en el artículo 4 del Decreto 306 de 1992), otros creen su propio procedimiento y algunos simplemente guarden prolongados silencios o se dediquen a enviar requerimientos a la entidad accionada. Este comportamiento obliga a interponer tutelas contra el juez de tutela por su pasividad en el cumplimiento del fallo, lo que viola el acceso a la administración de justicia, algo paradójico si se tiene en cuenta que dicho incidente fue creado precisamente para garantizar este principio (Olano, 2011, p. 343). Con estas demoras prolongadas lo que se está generando es una cadena sin fin para las víctimas: petición, tutela, incidente de desacato, tutela contra el juez de tutela por el no cumplimiento de la sentencia, etc.

Ahora bien, la Corte Constitucional inicialmente sostuvo una posición contraria a la arriba señalada. Para este tribunal, el artículo 52 del Decreto 2591 de 1991 establecía un procedimiento sencillo pero claro y completo sobre el incidente de desacato, que hacía innecesaria una reglamentación adicional o la remisión a otras normas. En palabras de la Corte:

El texto transcrito es completo en el sentido de que señala, no sólo el contorno de la figura del desacato, al establecer las circunstancias bajo las cuales éste se conforma, y las sanciones que el mismo conlleva, sino toda la estructura procesal de la actuación que debe surtirse para la declaración de que una persona ha incurrido en desacato y la imposición de la correspondiente sanción, al determinarse el medio que debe utilizarse, esto es, el trámite de un incidente, el juez competente, y el mecanismo para revisar y controlar la decisión sancionatoria (sentencia T-554 de 1996).

A pesar de esta posición de la Corte Constitucional, en la práctica muchos jueces aplican el 
procedimiento establecido en el artículo 137 del Código de Procedimiento Civil (Sánchez, 2013). Así las cosas, la "sencillez" de la fórmula procesal establecida en el Decreto 2591 de 1991 para el incidente de desacato está generando inefectividad de la tutela respecto a proteger los derechos de los accionantes, pues a pesar de los criterios jurisprudenciales expuestos por la Corte, en la práctica existen vacíos que son llenados por los jueces en forma disímil, especialmente en lo relativo a los términos judiciales.

Afortunadamente, la Corte Constitucional cambió recientemente su posición sobre el incidente de desacato en la sentencia C-367 de 2014, donde declaró la exequibilidad del artículo 52 del Decreto 2591 de 1991 en el entendido “de que el incidente de desacato allí previsto debe resolverse en el término establecido en el artículo 86 de la Constitución Política", es decir, los jueces tienen diez días hábiles para resolver de fondo el incidente de desacato, imponer las sanciones procedentes y lograr el cumplimiento del fallo de tutela. Por lo tanto, estamos a la espera del cumplimiento de dicho precedente por parte de los jueces de tutela.

Finalmente, este problema de las sentencias de jueces constitucionales bastante garantistas y la inefectividad de dichas decisiones en la práctica, conlleva discusiones más amplias, como en lo referente a los límites de la justicia constitucional para la emancipación o reivindicación de derechos (García y Uprimny, 2004), o los usos simbólicos del derecho (Lemaitre, 2009). Por ejemplo, en el campo de los derechos humanos hay una gran cantidad de normas que buscan la protección e indemnización de las víctimas del conflicto armado, el reconocimiento a sus derechos a la verdad, la justicia y la reparación. Normas que junto con las sentencias de la Corte Constitucional no han logrado una significativa reducción de las violaciones de los derechos humanos en Colombia o una efectiva reparación de las víctimas, sin embargo, estas sentencias pueden tener un valor simbólico, que en el caso concreto se evidenció con el cambio de actitud de algunas víctimas, las cuales antes de la sentencia de tutela mostraban cierto escepticismo frente a la reparación administrativa y hasta solicitaban desistir de sus casos, pero después del fallo de tutela su interés en lograr el reconocimiento de sus derechos aumentó. Este es un tema que requiere un mayor y juicioso estudio que el hasta ahora realizado.

\section{Referencias}

Corte Constitucional de Colombia. Sentencia T-025 de 2004. M. P.: Manuel José Cepeda.

Corte Constitucional de Colombia. Sentencia T-367 de 2014. M. P.: Mauricio González (Comunicado de prensa).

Corte Constitucional de Colombia. Sentencia T-462 de 2012. M. P.: Jorge Iván Palacio.

Corte Constitucional de Colombia. Sentencia T-554 de 1996. M. P.: Antonio Barrera.

Corte Constitucional de Colombia. Sentencia T-856 de 2011. M. P.: Nilson Pinilla. 
Corte Constitucional de Colombia. Sentencia T-868 de 2008. M. P.: Rodrigo Escobar.

Decreto 01 de 1984. Presidencia de la República.

Decreto 019 de 2012. Presidencia de la República.

Decreto 1281 de 2002. Presidencia de la República.

Decreto 1290 de 2008. Presidencia de la República.

Decreto 2591 de 1991. Presidencia de la República.

Decreto 306 de 1992. Presidencia de la República.

Decreto 3990 de 2007. Presidencia de la República.

Decreto 4800 de 2011. Presidencia de la República.

García, M. y Uprimny, R. (2004). Corte Constitucional y emancipación social en Colombia. En B. de S. Santos y M. García Villegas (Edits.), Emancipación social y violencia en Colombia. Bogotá: Editorial Norma.
Lemaitre, J. (2009). El amor en tiempos de cólera: derechos LGBT en Colombia. Sur - Revista Internacional de Derechos Humanos, VI(11), 79-98.

Ley 1437 de 2011.

Ley 1448 de 2011.

Ley 418 de 1997.

Olano García, H. A. (2011). Constitución Política de Colombia (Octava ed.). Bogotá: Ediciones Doctrina y Ley Ltda.

Resolución 1915 de 2008. Ministerio de la Protección Social.

Resolución 2349 del 28 de diciembre de 2012. Unidad para la Atención y Reparación Integral a las Víctimas.

Resolución 3069 de 2010. Agencia Presidencial para la Acción Social.

Sánchez, A. (2013). Eficacia del trámite incidental de desacato como mecanismo para lograr el cumplimiento de la orden del fallo de tutela. Revista de Derecho Público (30), 1-36.

Uprimny, R., Saffon, M. P., Botero, C. y Restrepo, E. (2006). ¿Justicia transicional sin transición? Verdad, justicia y reparación para Colombia. Bogotá: Editorial Norma. 